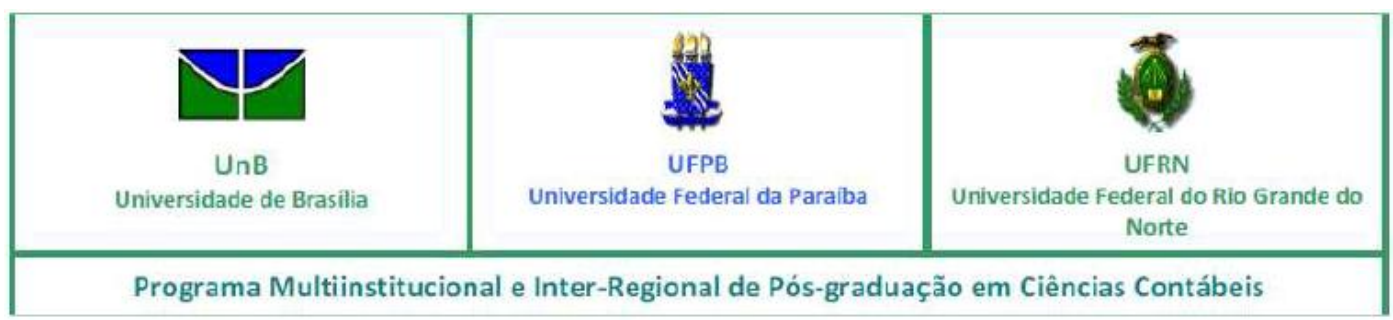

DETERMINANTES DA FRAUDE FINANCEIRA: a relação entre os aspectos de racionalidade e a desonestidade

AGAMENON DA COSTA MELO SEGUNDO

ORIENTADOR: PROF. DR. JOSÉ DIONÍSIO GOMES DA SILVA

\title{
NATAL/RN
}


DETERMINANTES DA FRAUDE FINANCEIRA: a relação entre os aspectos de racionalidade e a desonestidade

Dissertação apresentada ao Programa Multiinstitucional e Inter-Regional de Pós Graduação em Ciências Contábeis pela Universidade de Brasília, Universidade Federal da Paraíba e Universidade Federal do Rio Grande do Norte, como requisito à obtenção do título de Mestre em Ciências Contábeis.

Linha de Pesquisa: Contabilidade e Mercado Financeiro

Orientador: Prof. Dr. José Dionísio Gomes da Silva

NATAL - RN 
Melo Segundo, Agamenon da Costa.

Determinantes da fraude financeira: A relação entre os aspectos de racionalidade e a desonestidade/ Agamenon da Costa Melo Segundo. - Natal, 2016. 62f: il.

Orientador: Prof. Dr. José Dionísio Gomes da Silva.

Dissertação (Mestrado em Ciências Contábeis) - Universidade Federal do Rio Grande do Norte. Centro de Ciências Sociais Aplicadas. Programa Multiinstitucional e Inter-regional de Pós-graduação em Ciências Contábeis da Universidade de Brasilia, Universidade Federal da Paraiba e Universidade Federal do Rio Grande do Norte.

1. Desonestidade financeira- Dissertação. 2. Fraude financeira - Dissertação. 2. 3. Teoria da Perspectiva - Dissertação. 4. Regressão Linear Múltipla - Dissertação. I. Silva, José Dionísio Gomes da. II. Universidade Federal do Rio Grande do Norte. III. Titulo. 


\section{DETERMINANTES DA FRAUDE FINANCEIRA: a relação entre os aspectos de racionalidade e a desonestidade}

Dissertação apresentada como requisito parcial à obtenção do título de Mestre em Ciências Contábeis do Programa Multiinstitucional e Inter-regional de Pósgraduação em Ciências Contábeis da Universidade de Brasília, Universidade Federal da Paraíba e Universidade Federal do Rio Grande do Norte.

Aprovada em 13 de maio de 2016

BANCA EXAMINADORA:

Prof. Dr. JOSÉ DIONÍSIO GOMES DA SILVA

Universidade Federal do Rio Grande do Norte - UFRN

Orientador

Prof. Dr. Anderson Luiz Rezende Mól

Universidade Federal do Rio Grande do Norte - UFRN

Membro Examinador Interno

Prof. Dr. José Ribamar Marques de Carvalho

Universidade Federal de Campina Grande - UFCG

Membro Examinador Externo

Natal - RN

2016 


\section{AGRADECIMENTOS}

Meus agradecimentos começam pelas pessoas mais importantes que tenho em minha vida que são meus pais Agamenon e Maria Ivam. Não só esta dissertação como tudo de bom que possuo e vou chegar a possuir em minha vida devo a essas duas pessoas, que são exemplo de que com esforço, dedicação e, acima de tudo, honestidade, não existem limites para onde podemos chegar. Se hoje posso me tornar uma pessoa vitoriosa em meus objetivos, é por mérito do esforço de vocês. Em segundo lugar agradeço a meus irmãos Catharina e Joaquim que nem por um momento chegaram a duvidar de que conseguiria produzir este trabalho e que me inspiraram a continuar a luta para chegar ao fim. Agradeço também a todos em minha família que de uma forma ou de outra contribuíram para minha educação e formação.

Não poderia deixar de agradecer a meus professores que me ajudaram a crescer e a atingir o sucesso. Em primeiro lugar ao Prof. Dionísio que teve a paciência, a empatia e a humanidade de não desistir de mim, mesmo quando eu já havia desistido. A sua função foi a de um pai que não abandona um filho independente de quão grave ele erre. Por isso tudo, muito obrigado! Além disso, tenho muito a agradecer por todo o apoio do Prof. Mól que também acreditou no meu trabalho, no meu potencial e nas minhas ideias desde o início em que ele era o orientador e após não mais assumir o posto continuou agindo da mesma forma. A vontade de não decepcioná-los foi um dos mais importantes combustíveis que me moveram para a conclusão do presente trabalho.

Merecem também destaque o Prof. Atelmo, que há alguns anos, mesmo que inconscientemente, me deu um estímulo sem igual à persistir nesta área tão bela que é a contabilidade. À Prof ${ }^{a}$. Giovanna que ainda no momento do TCC da graduação me apoiou para que eu não me julgasse incapaz diante das dificuldades e para que as enfrentasse e não admitisse a derrota antes da batalha. A todos os outros professores do DCC da UFRN, bem como os da UFPB que tanto contribuíram com conhecimento acadêmico, meu muito obrigado! Não posso deixar de elucidar os professores que cederam o horário de aula para que aplicasse o experimento: Marke, Lis, Ronaldo e Mól.

$\mathrm{O}$ que seria de mim sem os amigos, em especial àqueles que nunca mudaram comigo, mesmo quando eu estava diferente: Italo e Selva. Além da galera do Papi que, 
sem saber, foram os únicos momentos de alegria que guardei na memória de tempos difíceis.

Devo muito também a Taliana que me ajudou em alguns casos até fisicamente, acreditando e me motivando a dar o meu melhor diante de uma situação tão complicada em que não achava estar apto a avançar. Saiba que apesar de tudo, nunca vou esquecer dos seus esforços para que eu progredisse e melhorasse como aluno, professor e como pessoa.

Não posso deixar de citar meus amigos e colegas da turma 28 do Programa Multi: Ana, Inajá, Poliandra, Marcelo e Victor Ranieri da PB e Camilinha, Nyalle e Fabiana do RN. Merecem ainda mais destaque pela proximidade e pelo contato tão intenso que tivemos: Carlos André, Victor Godeiro, Leandro e Roberto. Sobretudo esses dois últimos: o primeiro por de vez em quando, mesmo que eu não atendesse, ligar para mim só para saber como estava caminhando meu trabalho e; o segundo por ter sido esse amigo que me estendeu a mão e por nunca esquentar com meus muitos "vacilos". Meus queridos amigos: Muito Obrigado!

Por fim, agradeço à pessoa que vem me mostrando como as outras ciências funcionam, me incentivando a pensar sempre "fora da caixa" e que o mundo inteiro está à disposição daqueles que perseguem seus ideais. Ver que existe chance para mim fora da área que estudo e ver como as coisas são, também é força motriz para o meu sucesso. Sylvia seu suporte nesta reta final tem sido essencial para mim.

Este agradecimento é escrito em um momento e, como tal, não representa a amplitude do todo que fez de mim o que sou hoje. A todos os que me ajudaram e não foram citados, fica o meu mais sincero sentimento de gratidão. 
"Percebi ainda outra coisa debaixo do sol: Os velozes nem sempre vencem a corrida; os fortes nem sempre triunfam na guerra; os sábios nem sempre têm comida; os prudentes nem sempre são ricos; os instruidos nem sempre têm prestígio; pois o tempo e o acaso afetam a todos."

Eclesiastes 9, 11 


\section{RESUMO}

A teoria do Método Simples do Crime Racional trata das decisões acerca de uma atitude criminosa afirmando que são tomadas de forma racional, levando-se em conta o retorno obtido por esta ação, o risco de ser pego e a punição aplicável (BECKER, 1993). Entretanto, Kahneman e Tversky (1979) destacam que quando o indivíduo se depara com decisões que envolvem risco e ganhos financeiros, existem anomalias que ferem os axiomas da Teoria da Utilidade Esperada. Mead et al. (2009) evidenciam que os impulsos de obter ganhos financeiros e o auto controle de um indivíduo geram um comportamento heterogêneo quanto a sua honestidade. Diante do exporto o presente trabalho tem como objetivo geral investigar a relação entre a desonestidade financeira e a racionalidade, sob a luz da Teoria da Perspectiva entre os alunos da graduação dos cursos de Ciências Contábeis e Administração da Universidade Federal do Rio Grande do Norte. Para isto, utilizou-se de um experimento similar aos propostos por Mazar e Ariely (2006) e Mazar, Amir e Ariely (2008) para medir a desonestidade financeira e o questionário de Soares e Barbedo (2013) para a racionalidade. A amostra foi composta de 114 alunos dos referidos cursos e os experimentos realizados em sala de aula com a anuência e sem a interferência do professor da disciplina. Quanto ao tratamento dos dados optou-se um por um modelo de regressão linear múltipla. Após efetuados os testes, o modelo apresentou um $\mathrm{R}^{2}$ de 0,2641 e observou-se que a racionalidade influencia positivamente na desonestidade com um $\beta$ de 1,7450, indicando que quanto mais racional o indivíduo é, mais desonesto ele tende a ser, dentro das condições do experimento. Além disso, houve influência significativa de outras variáveis: Assiduidade em cerimônias religiosas e o período do aluno no curso. Por fím, apresentaram-se como limitações do trabalho o tamanho da amostra e falta de controle sobre algumas variáveis, principalmente no que concerne ao ambiente institucional.

Palavras-Chaves: Desonestidade. Teoria da Perspectiva. Regressão Linear Múltipla. 


\begin{abstract}
The theory of Simple Method of Rational Crime addresses the decisions about a criminal attitude stating that they are taken rationally, taking into account the return obtained by this action, the risk of getting caught and the applicable punishment (BECKER, 1993). However, Kahneman and Tversky (1979) points out that when the individual is faced with decisions that involve risk and financial gains, there are anomalies that hurt the axioms of the theory of expected utility. Mead et al. (2009) shows that the impulses of financial gain and self control of an individual generate a heterogeneous behavior towards his honesty. Based on the exposed, the present work have the objeticve to investigate the relationship between financial dishonesty and rationality by the light of the Prospective Theory among undergraduate students of Accounting and Administration of the Federal University of Rio Grande do Norte. In order to acomplish this, it was used a experiment similar to those proposed by Mazar and Ariely (2006) and Mazar, Amir and Ariely (2008) to measure the financial dishonesty and the survey of Soares and Barbedo (2013) for rationality. The sample consisted of 114 students of these courses and the experiments were conducted in the classroom with the consent and without the interference of the subject teacher. Regarding the processing of data, a multiple linear regression model was chosen. After the tests were performed, the model presented a $\mathrm{R}^{2}$ of 0.2641 and it was observed that rationality positively influences the dishonesty with a $\beta$ of 1.7450 , indicating that the more rational the individual is, more dishonest it tends to be, within the experimental conditions. In addition, there was a significant influence of other variables: assiduity in religious ceremonies and the period of the student in the course. Finally, as research restrictions there are the sample size and lack of control over certain variables, especially with regard to the institutional environment.
\end{abstract}

Keywords: Dishonesty. Prospect Theory. Multiple Linear Regression. 


\section{LISTA DE GRÁFICOS}

Gráfico 1. Função de valor..................................................................................... 18

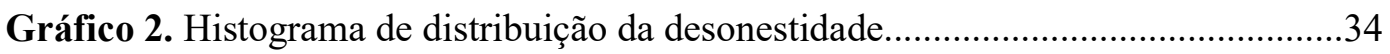




\section{LISTA DE QUADROS}

Quadro 1. Efeito das variáveis sobre a honestidade....................................................24

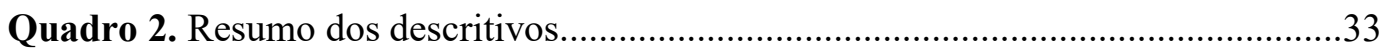

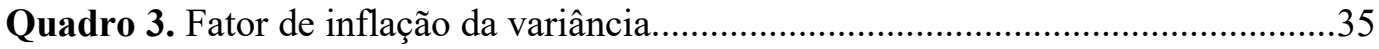

Quadro 4. Resumo dos teste de especificação....................................................................

Quadro 5. Regressão de desonestidade financeira.......................................................38 


\section{SUMÁRIO}

1 INTRODUÇÃO

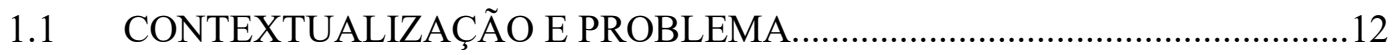

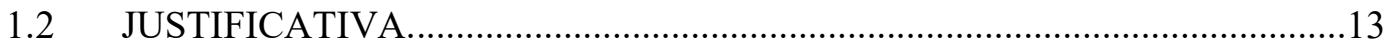

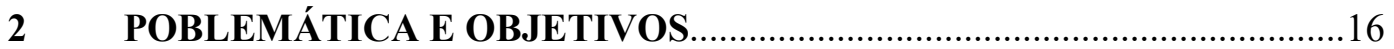

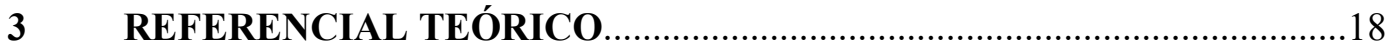

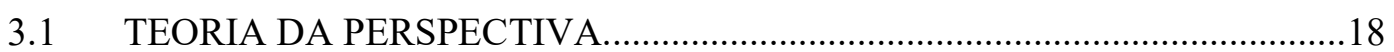

3.2 DESONESTIDADE FINANCEIRA...........................................................

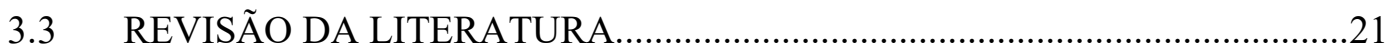

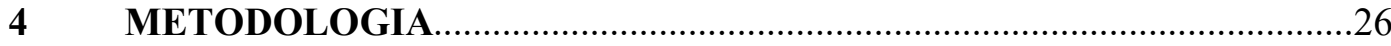

4.1 DESENHO DO EXPERIMENTO ORIGINAL ...................................................

4.2 DESENHO EXPERIMENTAL EMPREGADO..................................................

4.3 DESCRIÇÃO DA AMOSTRA....................................................................28

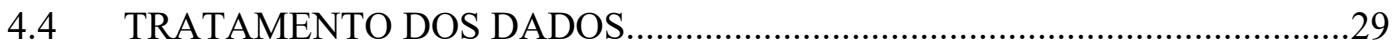

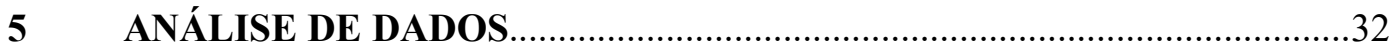

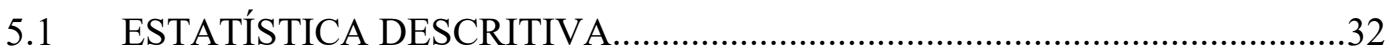

5.2 TESTES DE ESPECIFICAÇÃO DO MODELO REGRESSIVO........................34

5.3 ANÁLISE DO MODELO REGRESSIVO.......................................................36

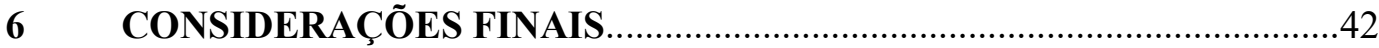

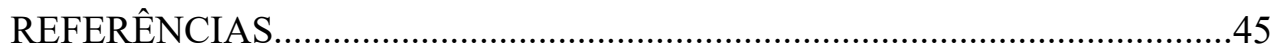

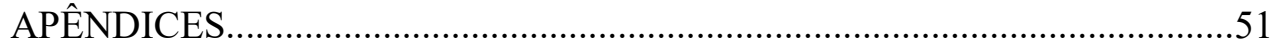




\section{INTRODUÇÃO}

\subsection{CONTEXTUALIZAÇÃO}

O ser humano é por natureza uma criatura que segue seus instintos. Desde os tempos mais primórdios, quando o homem passou a viver em sociedade, parte desses instintos vêm sendo reprimidos ou ignorados. Lowen (1977) define instinto como um ato impulsivo que não foi modificado nem pelo aprendizado nem pela experiência. Esses impulsos acabam levando as pessoas a tomarem, em determinadas circunstâncias, atitudes que nem sempre são racionais.

Com relação à desonestidade, Becker (1993) desenvolveu a teoria do Método Simples do Crime Racional, segundo esta, as decisões acerca de uma atitude criminosa são tomadas de forma racional, levando-se em conta o retorno obtido por esta ação, o risco de ser capturado e a punição aplicável. Tal, pode ser entendido como uma alusão à Teoria da Utilidade Esperada. Porém, essa não é uma decisão meramente racional, fatores éticos, sociais e culturais também influenciam este processo, conforme afirma o próprio Becker (1993).

Deste modo, Kahneman e Tversky (1979) destacam que quando o indivíduo se depara com decisões que envolvem risco e ganhos financeiros, existem anomalias que ferem os axiomas da teoria da utilidade esperada. Então, pode-se esperar que nas decisões que envolvem comportamento desonesto e ganho financeiro, tais fenômenos podem ser observados também.

Neste sentido, Ariely (2012) destaca que, além do risco e do retorno esperado, as decisões que envolvem comportamento fraudulento são influenciados por auto justificações, que podem ser consideradas irracionais. Ainda segundo o autor, as pessoas que cometem fraudes financeiras, em geral, não o fazem em demasia para não se sentirem culpadas, fraudam o suficiente para não ferir seus padrões éticos. Tal padrão de comportamento fere a teoria da utilidade esperada, uma vez que, em algumas situações, existe oportunidade para obter ganhos superiores que acabam sendo inexploradas por tais indivíduos.

As motivações e os vieses que influenciam a fraude financeira ainda são um campo pouco investigado. As pesquisas acerca do tema podem ser consideradas como recentes, com poucas pesquisas anteriores a 2009 e um número considerado escasso após tal período, conforme afirmam Rosembaum, Billinger e Stieglitz (2014). Ainda 
segundo os autores, tais pesquisas, quando apresentadas na forma de experimento que buscam medir a honestidade ou a propensão à ser verdadeiro classificam-se em cinco categorias: itens perdidos (lost/misdirected letters/itens); padrões de honra (honor standarts); dinheiro não merecido (undeserved money); resultado auto divulgado (selfreported outcomes); jogos de emissário-destinatário (sender-receiver games) e; tarefas desonestas (theft tasks). Além disso, observam-se poucas pesquisas que realizem levantamentos em suas metodologias, apesar de ser um meio válido, uma vez que contém vantagens éticas e morais e não há problemas associados com o controle das tentações ou com mascarar situações para os inqueridos (HOLLINGER; LANZAKADUCE, 1996).

Por fim, Mead et al. (2009) evidenciam que os impulsos de obter ganhos financeiros e o auto controle de um indivíduo geram um comportamento heterogêneo quanto a sua honestidade. Logo, desonestidade financeira pode ser tida coma uma função de parâmetros econômicos (risco/retorno) e de custos e barreiras psicológicas de honestidade (ROSEMBAUM; BILLINGER; STIEGLITZ, 2014).

\subsection{JUSTIFICATIVA}

Conforme já comentado, a desonestidade não depende somente de fatores psicológicos e mecanismos de controle podem inibir e controlar tal comportamento. Aumentar a probabilidade de detecção de atividade fraudulenta bem como identificar os responsáveis por tal podem servir como ferramenta de combate aos desvios.

Neste contexto a contabilidade pode ser inserida como peça fundamental no controle da desonestidade. Sá (2006) evidencia que a contabilidade, enquanto fonte de informações do comportamento da riqueza das aziendas, possui utilidade para, dentre outras funções, atividades de crédito, financiamento e de controle. A contabilidade pode ainda servir como meio de controle interno, produzindo informação acerca de eficiência e eficácia de processos, além de ser métrica para verificação de possíveis desvios (GARRISON; NOREEN; BREWER. 2007).

De forma análoga, Hendricksen e Van Breda (1999) afirmam que as considerações éticas exercem influência ampla em toda a contabilidade. Os autores ainda estabelecem, baseados no pronunciamento do SFAC 2, como característica qualitativa da informação contábil a Confiabilidade e afirmam que a informação deve representar fidedignamente, de forma verificável e neutra a realidade dos fatos 
contábeis. Isto indica que a informação contábil ganha valor à medida que é apresentada livre de vícios.

Em se tratando do gasto público, os controles deveriam ser ainda mais eficazes, uma vez que deveria haver um interesse da sociedade sobre a destinação destes recursos. Mecanismo como os Portais da Transparência, o advento das leis de Responsabilidade Fiscal, Acesso à Informação e de Transparência permitem a qualquer cidadão o acompanhamento de qualquer lugar e a qualquer hora da execução dos gastos do governo em todas as esferas (PINA; TORRES; ACERETE. 2007; MATOS. 2015). Apesar das melhorias das práticas de governança, ainda é comum serem noticiados escândalos envolvendo o dinheiro público.

A corrupção do setor público é um dos males da sociedade brasileira, comprometendo diretamente a posição das nações em índices de desenvolvimento humano. O Brasil atingiu em 2012 a posição de sétima maior economia do mundo, entretanto, ainda é considerado como país em desenvolvimento por apresentar altos índices de analfabetismo (10\%) e corrupção percebida (ABREU; MEIRELES; CUNHA, 2015). De forma análoga, Bussell (2010) cita o caso indiano, onde se instaurou uma corrupção burocrática endêmica, em que a participação popular e os índices de transparência são baixos.

O Brasil está entre os países com maior índice de desigualdade social, com 70\% dos brasileiros considerando a corrupção como um dos principais problemas do país, de acordo com o Transparency International em 2012 (DA ROSA, et al. 2015). Rocha (2011) afirma que desvios e má gestão de recursos públicos são os maiores responsáveis pelas tragédias vividas pelo povo.

Entretanto, o problema da desonestidade não é exclusivo do setor público. Jensen e Meckling (1976) quando propuseram a Teoria da Agência, afirmaram que o conflito de interesse entre os Agentes e Principais podem levar ao problema de Agência e o próprio Jensen (2003) afirma que o agente pode incorrer em desvios de ética para atingir seus interesses pessoais e que é preciso atenção na elaboração das políticas de incentivo e alinhamento de interesse além de atenção aos controles da entidade. Arrow (1968), afirma que quando há assimetria de informação e não há monitoramento suficiente por parte do principal, nesta relação podem incorrer também riscos morais (moral hazzard) e desvios de conduta por parte do agente.

Diante de todo o exposto, entende-se que conhecer quais justificativas podem inibir de forma mais eficiente a atitude desonesta ou ainda como fazer com que o 
indivíduo se sinta mais culpado ao cometer tal atitude, deve ser objeto de estudo, uma vez que pode ajudar a desenvolver mecanismos de controle mais eficazes. 


\section{POBLEMÁTICA E OBJETIVOS}

Diante de tal cenário, a relação esperada entre a desonestidade financeira e racionalidade é positiva, uma vez que indivíduos com maior senso de racionalidade tenderiam a fraudar mais em situações de baixo risco ou de alto retorno esperado, maximizando assim seus ganhos. Portanto o presente estudo busca identificar a relação existente entre a desonestidade financeira e a racionalidade à luz da teoria da perspectiva e espera-se que as relações sejam positivas, isto indicaria que quanto maior a racionalidade do indivíduo, mais desonesto ele tenderia a ser.

Dito isto, o presente estudo tem como problemática: qual a relação observada ente a racionalidade e a desonestidade financeira?

A resposta a esse problema de pesquisa poderá contribuir com uma melhor entendimento do tema uma vez que, conforme discutido na introdução, a desonestidade financeira possui um comportamento heterogêneo quanto a uma séries de situações. Além disso, algumas variáveis intrínsecas do indivíduo podem influenciar no seu comportamento e nos seus padrões éticos.

Investigar em quais situações, quais variáveis e de que forma elas influenciam nos desvios de comportamento, pode ser considerado importante pois as políticas de controle podem ser mais eficientes e eficazes no combate à fraude financeira sendo elaboradas com o entendimento de como a desonestidade é cometida.

O presente estudo tem como objetivo geral investigar a relação entre a desonestidade financeira e a racionalidade, sob a luz da Teoria da Perspectiva entre os alunos da graduação dos cursos de Ciências Contábeis e Administração da Universidade Federal do Rio Grande do Norte.

Como objetivos específicos tem-se:

- Realizar um experimento que permita mensurar o nível de desonestidade financeira bem como a racionalidade dos indivíduos;

- Analisar que outras variáveis influenciam na desonestidade financeira e;

- Analisar os resultados obtidos no experimento, utilizando um modelo de regressão linear múltipla.

O questionário, apesar de preservar a identidade do respondente e dar liberdade de resposta, pode não ser a metodologia mais indicada para o tema da desonestidade, uma vez que o indivíduo pode se declarar como honesto, mas diante de uma situação de possíveis ganhos financeiros, este pode acabar cedendo. Logo, o experimento seria a 
metodologia mais indicada para mensurar a desonestidade (NAQUIN; KURTZBERG; BELKIN. 2010). Quanto à racionalidade, existem ferramentas validadas, inclusive a proposta pelos próprios autores da Teoria da Perspectiva (KAHNEMAN; TVERSKY. 1979) onde é possível determinar com confiabilidade a sensibilidade do respondente aos vieses da racionalidade.

Entretanto, analisar apenas duas variáveis, desonestidade e racionalidade, diante de um tema complexo como este pode não ser suficiente. Nas pesquisas anteriores sobre o tema, conforme ver-se-á no tópico 3 deste trabalho, algumas variáveis são recorrentes, sendo subdivididas em variáveis controláveis de acordo com a natureza do experimento e as variáveis de efeito fixo. Para estas últimas destaque-se o Gênero, a Idade, Renda, Área de Formação e Religiosidade (ROSEMBAUM; BILLINGER; STIEGLITZ, 2014). Estas mesmas podem ser mesuradas em um cenário experimental sem prejuízo, viés ou esgotamento do voluntário.

A relação entre tais variáveis necessita de tratamento estatístico para uma melhor compreensão das mesmas. Gujarati e Porter (2011) definem que um modelo regressivo é aquele em que se estuda a dependência de uma variável em relação às variáveis exploratórias ou independentes, visando estimar os valores da primeira em função de valores predeterminados das segundas.

Assim, o presente trabalho está dividido em 6 partes. As duas primeiras contemplavam a introdução ao tema e a problematização e objetivos, respectivamente. A próxima sessão fará uma revisão da literatura até o presente momento, destacando as principais teorias que norteiam a pesquisa, bem como estudos relacionados ao tema. $\mathrm{Na}$ quarta parte serão apresentados os procedimentos metodológicos empregados, assim como o modelo experimental. Em seguida os resultados apurados serão discutidos e por fim, na parte 6 , serão apresentadas as considerações finnais e recomendações de pesquisas futuras. 


\section{REFERENCIAL TEÓRICO}

\subsection{TEORIA DA PERSPECTIVA}

As mudanças e fenômenos observados no mercado financeiro, segundo pesquisas, podem ser determinadas por padrões de comportamento e de emoções (FERREIRA, 2008). Os erros cognitivos podem influenciar o processo de decisão de investidores e como esses padrões de comportamento podem determinar mudanças no mercado (HALFELD; TORRES, 2001).

Um número considerável dessas pesquisas utilizam como trabalho seminal o de Kahneman e Tversky (1979) que propõe a Teoria da Perspectiva. Segundo os autores quando em vista de uma decisão que envolve risco, os indivíduos passam por duas fases de pensamento: edição (onde as informações são decifradas e na maioria das vezes simplificadas) e avaliação (onde são comparadas as alternativas e é escolhida a de maior valor). Entretanto, quando a decisão é tomada, as preferências do indivíduo acabam influenciando a decisão e gerando anomalias (KAHNEMAN; TVERSKY, 1979), dos quais se destacam o efeito certeza, efeito reflexo e o enquadramento.

Melo (2014) evidencia que os indivíduos tendem a ser avessos ao risco em relação aos ganhos e propensos quando diante de perdas, evidenciando assim a aversão à perda. Este conceito baseia-se na constatação de que as pessoas sentem muito mais a dor da perda do que o prazer obtido com um ganho equivalente.

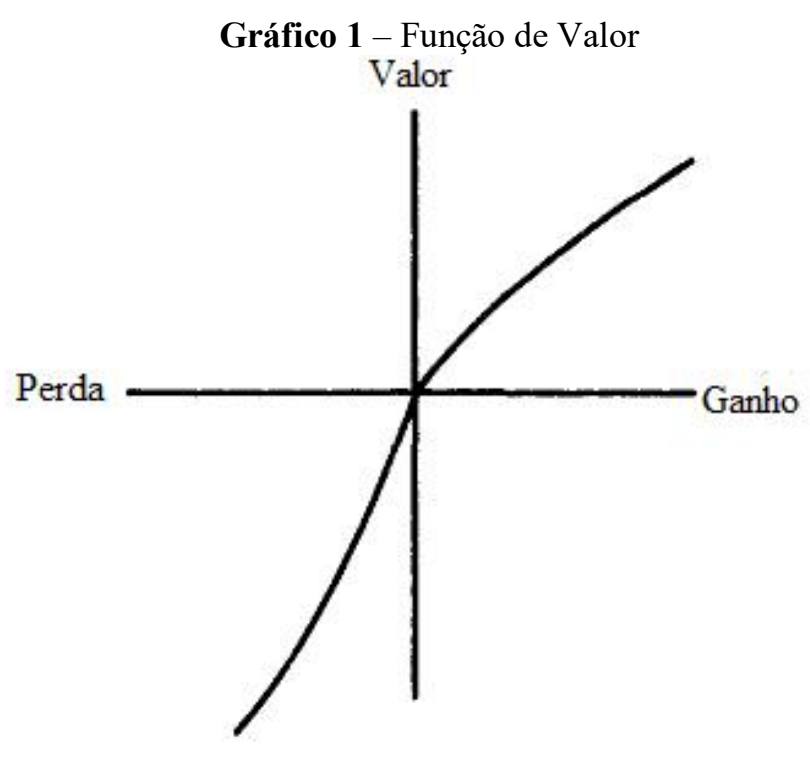

Fonte: Kahneman e Tversky, 1979. 
Destaca-se ainda três pontos da Teoria de Perspectiva que violam axiomas da teoria da utilidade esperada: as decisões são tomadas de acordo com os ganhos e perdas, não como as variações de posição patrimonial que elas geram; a função da utilidade esperada é côncava em relação aos ganhos e convexa em relação às perdas e; os indivíduos sentem muito mais a dor de uma perda do que o prazer de um ganho equivalente (KAHNEMAN; TVERSKY, 1979. Id., 1984. Id., 1992). O Gráfico 1 explicita tal pensamento e representa a função do valor percebido em função de um ganho ou perda financeira.

Diante do exposto, pode-se observar que a Teoria da Perspectiva traz à luz situações onde o comportamento do indivíduo fere a Teoria da Utilidade Esperada. No sub tópico a seguir será discutida a questão da desonestidade financeira.

\subsection{DESONESTIDADE FINANCEIRA}

Nos dias contemporâneos é notório o número crescente de escândalos de desvios de dinheiro público ou privado. Há no pais uma evidenciação maior dos desvios de recursos públicos, uma vez que são mais bem divulgados pelos meios de comunicação em massa. Chaia e Teixeira (2001) afirmam que tal processo de corrupção é o principal empecilho para o desenvolvimento da nação, uma vez que a desonestidade da classe política força os empresários a produzirem desvios ainda maiores para obterem contratos no futuro, afirmando que a corrupção, em último caso, pode comprometer toda uma sociedade.

O aumento do número de casos de corrupção, na visão de Sodré e Alves (2010) se daria principalmente por quatro fatores, não excludentes entre si:

- Aumento do Ganho Potencial do Ato Corrupto - no Brasil, a punição para determinados atos é a mesma, independentemente dos valores desviados;

- Aumento do Poder Discricionário Local - quanto maior o orçamento à disposição do gestor, maior será seu poder de escolher quais serviços serão necessários e mais facilmente poder-se-á desviar pequenas quantidades de recursos; 
- Aumento da Pressão de Rent-Seekers: é comum observar em processos licitatórios o oferecimento de vantagens, por parte de empresários aos licitantes, em troca de favorecimento no processo e;

- Conluio com a Corrupção Federal: com os recursos passando por várias esferas da gestão, há uma tendência ao favorecimento de localidades que tenham aceitado envolvimento em desvios anteriores.

Entretanto, pessoas que se sujeitam a este tipo de situação não são, na maioria dos casos, diferentes psicologicamente dos que não se envolvem. Becker (1993) acredita que o comportamento criminoso não é diferente do pensamento racional da maioria das pessoas. Para o autor, uma atitude fraudulenta só é tomada após o indivíduo ponderar os riscos de ser flagrado realizando tal ato, a punição a que é passível de ser empregada e os benefícios advindos de tal atividade, similar a uma decisão tomada através da Teoria da Utilidade Esperada. Porém o próprio Becker (1993) afirma que este não é o único pensamento levado em consideração ao se avaliar uma atitude fraudulenta.

A questão comportamental também é levada em consideração. Para Heidenheimer (1970) a corrupção pode ser classificada em 3 tipos: corrupção branca, quando existe lei que proíbe determinada atitude, mas a sociedade a tolera; corrupção preta, que é quando a norma e a sociedade punem um comportamento e; corrupção cinza, que é quando há controvérsia entre os participantes de uma sociedade.

Um dos objetivos das áreas que envolvem a gestão de recursos e pessoas, como a Contabilidade e a Administração, é fortalecer as ferramentas de controle das entidades. Evitar a desonestidade financeira também é tarefa fundamental de tais profissionais. Considerando a atitude fraudulenta como uma decisão da Teoria da Utilidade Esperada um dos fatores que podem inibir a corrupção seria aumentando a probabilidade de detecção ou a punição aplicável. Sobre tal pensamento, Nagin e Pogarsky (2003) afirmam ser mais eficaz aumentar a probabilidade em detrimento a aumentar a punição na mesma proporção.

Tais pressuposições sobre atitudes desonestas consideram apenas percepções externas aos indivíduos. Todavia, estudos das áreas de Sociologia, Psicologia, Economia Comportamental, Neurociências, entre outras, também consideram aspectos internos como influenciadores do comportamento para eventos que envolvam questões de desonestidade. E ainda faz-se necessário analisar os níveis de honestidade a que os indivíduos se sujeitam, não podendo classifica-los meramente como éticos, que nunca 
mentem, ou econômicos, que mentem quando o benefício associado a ela é preferível ao que se obteria com a verdade (GNEEZY, 2005. GIBSON; TANNER; WAGNER, 2012).

Mazar, Amir e Ariely (2008), evidenciam que as pessoas não mentem o máximo, mesmo diante de uma probabilidade praticamente nula de serem detectadas ou de ganhos financeiros decorrentes de tais atos, para tentar manter uma auto imagem de pessoa honesta. Tal comportamento, poderia se justificar pelo fato do Superego, parte do cérebro que, segundo Freud, representa as normas sociais no interior da mente do indivíduo, servindo como juiz, punindo ou recompensando-o por suas atitudes (MAZAR; ARIELY, 2006).

A compreensão dos fatores que levam um indivíduo a cometer uma fraude financeira, bem como o que pode inibir o mesmo, ou ainda quais características em comum guardam as pessoas desonestas, podem se tornar relevantes para a elaboração de políticas de controle mais eficientes. No sub tópico a seguir discutir-se-á os principais vieses presentes na literatura que influenciam na fraude financeira.

\subsection{ESTUDOS SOBRE FRAUDES FIANACEIRAS}

Diversas pesquisas recentes vem buscando investigar quais são as variáveis que podem incentivar ou inibir a realização de fraudes financeiras. Os trabalhos de Mazar e Ariely (2006) e Mazar, Amir e Ariely (2008) identificaram que a auto imagem serve como uma espécie de freio para as coibir atitudes antiéticas, entretanto, existe uma "margem de manobra" que permite que o indivíduo cometa pequenas fraudes sem, contudo, se sentir moralmente culpado. Os autores concluem que, em média, a maioria do indivíduos tendem a fraudar em benefício próprio, mas só o suficiente para não se sentir criminoso.

Em um experimento similar, Gino, Ayal e Ariely (2013), constataram que outro fator determinante para o comportamento desonesto reside no fato de quem se beneficiará com o resultado da ação. Os autores observaram que quando os ganhos financeiros advindos da trapaça podem ser transmitidos para outros indivíduos, mesmo que sejam desconhecidas, as pessoas tendem a fraudar mais do que se os benefícios viessem apenas para eles mesmos. Caso haja uma relação amistosa entre os envolvidos, as fraudes tendem a se intensificar. Okeke e Godlonton (2014) encontraram resultados 
parecidos, observando que pessoas tendem, em média, a fraudar mais quando os beneficiados com tal ato são pessoas mais necessitadas.

Outro fator importante observado reside no fato de que um dos atenuantes da culpa sentida pelo indivíduo que pratica fraudes financeiras é o de imaginar que outras pessoas também realizam as mesmas atividades, porém causando mais danos ou em maior intensidade do que as praticadas por eles (MCKENZIE, 2009). Já Erat (2013) constatou que quando se pode delegar uma atitude desonesta a terceiros, mesmo havendo perda financeira, as pessoas tendem a preferir ganhos menores e transferir indiretamente o peso moral da fraude a outros.

Já a pesquisa de Gino e Wiltermuth (2013) testaram se a inteligência do indivíduo influencia no comportamento antiético, porém não foram encontradas evidências estatisticamente significantes. Entretanto, o mesmo trabalho testou outro grupo de respondentes e constatou que existe relação positiva entre a criatividade e a fraude financeira, o que indica que quanto mais criativo o indivíduo, mais facilmente ele encontra motivos para não se sentir culpado por burlar o sistema e cometer a fraude.

No Brasil, observou-se somente a dissertação de mestrado de Santos (2011)que modificou o experimento de Mazar, Amir e Ariely (2008) e observou que um lembrete moral quanto à religiosidade não afeta significativamente a desonestidade, nem ao fato de ter que informar à fonte pagadora qual foi o seu desempenho no experimento (diminuindo ainda mais sua probabilidade de detecção).

O trabalho de Azar, Yosef e Bar-Eli (2013) constatou, através de um experimento em um restaurante que envolvia a um garçom devolvendo um troco maior do que o correto, que mulheres desacompanhadas tendem a ser mais honestas na situação apresentada. No mesmo trabalho os autores constataram que se os valores forem mais expressivos, as pessoas tendem a notificar o erro e devolver o excedente.

A lista de pesquisas que tratam de questões relativas à racionalidade é cada vez maior, entretanto, conforme sintetizado por Rosembaum, Billinger e Stieglitz (2014), podem-se extrair da literatura as seguintes variáveis que foram objeto de pesquisas, sendo subdivididas em de efeito fixo: Gênero, Rendimento, Religiosidade, Idade, Formação; e de efeito controlado no experimento: Tamanho da Participação, Monitoramento, Grupos, Lembretes Morais (Moral Priming) e Custo Intrínseco da Desonestidade.

O Quadro 1 apresenta de forma resumida os principais efeitos de cada variável sobre a honestidade e o inverso pode ser dito sobe a desonestidade, podendo ser 
positivo, negativo ou neutro quando não apresenta relação ou ainda inconclusivo, quando não há evidência estatisticamente relevante para a relação. Para facilitar o entendimento, no Quadro 1 a variável de gênero foi considerada como sendo feminino e a formação em Ciências Econômicas.

Ainda falando da variável de gênero, os trabalhos de Franzen e Pointner (2013); Abeler, Becker e Falk (2014); Lewis et al. (2012); Rosenbaum et al. (2012); Cappelen, Sørensen e Tungodden (2013); Childs (2012); Erat e Gneezy (2012); Gylfason, Arnardottir e Kristinsson (2013); Holm e Kawagoe (2010); Lundqvist et al. (2009) e; Gravert (2013) não apresentaram resultados que indiquem que o gênero produza algum efeito sobre a honestidade nos seus experimentos. Já Conrads et al. (2013); Id. (2014); Houser, Vetter e Winter (2012); Azar, Yosef e Bar-Eli (2013); Dreber e Johanneson (2008); Friesen e Gangadharan (2013) observaram que as mulheres são mais propensas a contar a verdade do que os homens, apesar de, em situações de desonestidade, apresentarem maior propensão a inventar desculpas.

Quanto à religiosidade, Utikal e Fischbacher (2013) observaram em um experimento comparando comportamento de universitárias e de freiras da ordem Franciscana, que as mais religiosas tendem a apresentar um comportamento menos ganancioso e, consequentemente, manipulam seus resultados para obterem um menor rendimento, indicando um conflito entre as aversões à mentira e à ganância, prevalecendo a segunda. Já Abeler, Becker e Falk (2014), em um experimento comparativo entre resultados em laboratório e via telefone, observaram que não há influência de qualquer característica individual sobre a desonestidade, ou seja, nem a religião nem a frequência de participação em cerimônias influencia na desonestidade. Ruffle e Tobol (2014) também não apresentaram diferença estatisticamente significante para a religiosidade dos indivíduos.

Quanto à área de formação, apenas o trabalho de Houser, Vetter e Winter (2012) não apresentou diferença para a variável. Foi possível observar que alunos de áreas relacionadas com a economia tendem a fraudar mais em situações de baixo risco de detecção, isto se justificaria por uma maior exposição ao Equilíbrio de Nash e uma maior racionalização por parte destes indivíduos (LEWIS, et al. 2012. CHILDS, 2012. LUNDQUIST, et al. 2009).

$\mathrm{O}$ número de participantes em uma tarefa desonesta gera resultados heterogêneos. Conrads et al. (2013) afirmam que quando a tarefa é feita em grupo, é mais difícil de detectar o responsável pela fraude e esta tende a ser mais recorrente. Já 
Sutter (2009) afirma que o grupo pode fazer pressão para que nenhum de seus membros cometa desvios morais.

Quadro 1 - Efeito das variáveis sobre a honestidade

\begin{tabular}{|c|c|c|c|}
\hline Efeito & Gênero: Feminino & Efeito & Tamanho da Participação \\
\hline $\begin{array}{c}\text { Neutro ou } \\
\text { Inconclusivo }\end{array}$ & $\begin{array}{l}\text { Franzen e Pointner, 2013; Abeler, } \\
\text { Becker e Falk, 2014; Lewis et al., } \\
\text { 2012; Rosenbaum et al., 2012; } \\
\text { Cappelen, Sørensen e Tungodden, } \\
\text { 2013; Childs, 2012; Erat e Gneezy, } \\
\text { 2012; Gylfason, Arnardottir e } \\
\text { Kristinsson, 2013; Holm e Kawagoe, } \\
\text { 2010; Lundqvist et al., 2009; Gravert, } \\
\text { 2013. } \\
\text { Conrads et al., 2013; Id., 2014; } \\
\text { Houser, Vetter e Winter, 2012; Azar, } \\
\text { Yosef e Bar-Eli, 2013; Dreber e } \\
\text { Johanneson, 2008; Friesen e } \\
\text { Gangadharan, 2013. }\end{array}$ & $\begin{array}{c}\text { Neutro ou } \\
\text { Inconclusivo }\end{array}$ & $\begin{array}{c}\text { Azar, Yosef e Bar-Eli, } 2013 . \\
\text { Conrads et al., 2014; Dreber } \\
\text { e Johanneson, 2008. }\end{array}$ \\
\hline Efeito & Religiosidade & Efeito & Monitoramento \\
\hline Positivo & Utikal e Fischbacher, 2013. & Positivo & $\begin{array}{l}\text { Bateson, Nettle e Roberts, } \\
\text { 2006; Mazar, Amir e Ariely, } \\
\text { 2008; Zhong, Bohns e Gino, } \\
2010 .\end{array}$ \\
\hline $\begin{array}{l}\text { Neutro ou } \\
\text { Inconclusivo }\end{array}$ & $\begin{array}{l}\text { Abeler, Becker e Falk, 2014; Ruffle e } \\
\text { Tobol, } 2014 .\end{array}$ & $\begin{array}{c}\text { Neutro ou } \\
\text { Inconclusivo }\end{array}$ & $\begin{array}{c}\text { Gamliel e Peer, 2013; Holm } \\
\text { e Kawagoe, } 2010 .\end{array}$ \\
\hline Efeito & Idade & Efeito & Grupos \\
\hline $\begin{array}{c}\text { Neutro ou } \\
\text { Inconclusivo }\end{array}$ & $\begin{array}{l}\text { Franzen e Pointner, 2013; Abeler, } \\
\text { Becker e Falk, 2014; Childs, } 2012 .\end{array}$ & Negativo & Conrads et al., 2013. \\
\hline Positivo & Conrads et al., 2013. & $\begin{array}{c}\text { Neutro ou } \\
\text { Inconclusivo }\end{array}$ & $\begin{array}{l}\text { Azar, Yosef e Bar-Eli, } \\
\text { 2013; Cohen et al., } 2009 .\end{array}$ \\
\hline Negativo & Friesen e Gangadharan, 2013. & Positivo & Sutter, 2009. \\
\hline Efeito & Renda & Efeito & Moral priming \\
\hline $\begin{array}{c}\text { Neutro ou } \\
\text { Inconclusivo }\end{array}$ & $\begin{array}{l}\text { Franzen e Pointner, 2013; Abeler, } \\
\text { Becker e Falk, 2014; Haan e } \\
\text { Kooreman, 2002; Childs, } 2012 .\end{array}$ & Positivo & $\begin{array}{l}\text { Keizer, Lindenberg e Steg, } \\
\text { 2008; Mullen e Nadler, } \\
\text { 2008; Bucciol e Piovesan, } \\
\text { 2011; Aveyard, } 2014 .\end{array}$ \\
\hline Efeito & Formação (Economia) & Efeito & $\begin{array}{c}\text { Custos Intrínsecos da } \\
\text { Mentira }\end{array}$ \\
\hline $\begin{array}{l}\text { Neutro ou } \\
\text { Inconclusivo }\end{array}$ & $\begin{array}{l}\text { Lewis et al., 2012; Childs, 2012; } \\
\text { Lundquist et al., } 2009 .\end{array}$ & Positivo & $\begin{array}{c}\text { Utikal e Fischbacher, 2013; } \\
\text { Cappelen, Sørensen e } \\
\text { Tungodden, 2013; Gino, } \\
\text { Ayal e Ariely 2013. }\end{array}$ \\
\hline
\end{tabular}

Fonte: Adaptado de Rosembaum, Billinger e Stieglitz (2014). 
O tamanho da participação, ou seja, o valor do ganho financeiro obtido com a atitude desonesta, pode ser irrelevante para a prática de tal ato. Entretanto, expor o indivíduo repetidamente a situações onde a fraude pode ser cometida pode gerar uma espécie de cansaço moral e gerar um comportamento antiético após determinado número de repetições (MAZAR; AMIR; ARIELY. 2008). Ainda sobre o tema, nas pesquisas de Conrads et al.( 2014) e Dreber e Johanneson (2008), foram observadas evidências de que quando a monta em dinheiro é relativamente alta, a honestidade tende a aumentar, possivelmente explicado pelo senso moral frear o comportamento. Porém, o oposto também pode ocorrer, quando os recursos são poucos, o custo da desonestidade pode ser superior ao benefício econômico por ela gerado conforme o já citado trabalho de Azar, Yosef e Bar-Eli (2013).

Sob a mesma ótica, aumentar o sentimento de culpa, ou mesmo diminuí-lo, afeta positivamente a honestidade. O trabalho de Cappelen, Sørensen e Tungodden (2013) evidencia que inserir uma característica pessoal do passado do respondente pode fazê-lo a expressar um sentimento interior e aumentar sua honestidade. Em contrapartida, podese inferir que quando altruísmo está como justificativa da desonestidade, esta tende a aumentar (UTIKAL; FISCHBACHER, 2013. GINO; AYAL; ARIELY, 2013).

Lembretes morais (Moral Priming), também são unanimidade nas pesquisas. Sejam sobre questões éticas (KEIZER; LINDENBERG; STEG, 2008. MULLEN; NADLER, 2008. BUCCIOL; PIOVESAN, 2011) ou religiosas (AVEYARD. 2014), a honestidade das pessoas tende a aflorar diante de lembretes e de diminuir diante de situações claramente desagradáveis moralmente.

Diante de todo o exposto, pode-se concluir que o certo e o errado para a sociedade depende de um grande número de situações e variáveis. Um mesmo indivíduo pode apresentar comportamento moral heterogêneo em diferentes cenários e algumas características tendem a permear e possivelmente explicar tal comportamento. Logo, entender quais características influenciam e de que forma é fundamental para combater a desonestidade. No tópico a seguir será discutida a metodologia empregada no experimento, bem como a delimitação da amostra e o tratamento dos dados. 


\section{METODOLOGIA}

O presente estudo pode ser considerado, quanto aos objetivos, como pesquisa exploratória. Na visão de Raupp e Beuren (2003), esta classificação refere-se a trabalhos cujo tema é pouco explorado, buscando trazer a discussão sobre determinado assunto ou torna-lo mais claro.

Quanto aos fins, é considerado um estudo quantitativo. A abordagem quantitativa ocorre quando os dados são expressos, na medida do possível, em dados numéricos, sem o pesquisador fazer juízo de valor, permitindo que os dados e lógica levem a uma conclusão real (MARCONI; LAKATOS, 1999).

Quanto aos meios, será empregado um experimento. Para Raupp e Beuren (2003) na pesquisa experimental o pesquisador cria um cenário desejado no qual manipula variáveis, tendo a capacidade de observar os efeitos de tal manipulação. Além disso, para este tipo de pesquisa destaca-se a casualidade, de modo que, qualquer designação dada a um sujeito do universo, possua igual probabilidade de poder ser escolhida a qualquer outro objeto.

\subsection{DESENHO DO EXPERIMENTO ORIGINAL}

Para investigação dos objetivos do presente estudo, optou-se pela realização de um experimento similar ao proposto originalmente por Mazar e Ariely (2006) e Mazar, Amir e Ariely (2008), classificado como theft-task.

$\mathrm{O}$ original consistia em um conjunto de 20 matrizes de $4 \times 3$ contendo 12 números de três dígitos, sendo duas as casas decimais, por exemplo: 3,76. Em cada uma dessas matrizes haveria somente uma possível combinação de números que, quando somandose dois a dois, obter-se-ia uma resultado exatamente igual a 10,00. A todos os participantes do experimento era concedido o tempo de 5 minutos para realizar a operação no máximo de matrizes possíveis e lhes era informado que receberiam US\$ 0,50 (cinquenta centavos de dólar) por cada matriz resolvida corretamente.

Entretanto, os participantes eram divididos em dois grupos, um de controle e outro em que a desonestidade era permitida. No grupo de controle, um fiscal conferia o número de respostas corretas que cada participante havia conseguido, obtendo-se assim um desempenho médio real. No outro grupo, era informado que cada respondente 
deveria recordar quantas matrizes haviam sido feitas corretamente e anotar em uma ficha de cobrança que seria apresentada a outro fiscal que faria o pagamento com base no número que constasse nessa ficha, sem a necessidade da conferência das referidas matrizes. Após efetuado o pagamento, todas as páginas contendo matrizes eram lançadas em um triturador de papéis, eliminando qualquer possível vestígio de trapaça.

Após isso, eram comparados os números de respostas corretas dos dois grupo que deveriam, em média, ser iguais, uma vez que os indivíduos deveriam possuir níveis de inteligência matemática similares. Sendo observada diferença entre os dois, a mesma poderia ser atribuída à desonestidade.

Em tal experimento não havia para os participantes divulgação de qual deles havia tido o melhor desempenho, evitando assim o viés de o respondente fraudar para ser considerado o com maior capacidade de raciocínio matemático ou melhorar a autoestima dos mesmos, sendo os resultados apresentados de forma desonesta motivados somente por interesses financeiros (MAZAR; AMIR; ARIELY, 2008).

\subsection{DESENHO EXPERIMENTAL EMPREGADO}

Para a presente pesquisa, o experimento foi modificado, não houve grupo de controle para a desonestidade. Em contrapartida foi considerada a desonestidade individualizada de cada voluntário. Uma vez que buscou testar a relação entre racionalidade sob o prisma da Teoria da Perspectiva e a desonestidade financeira, o experimento foi seccionado em duas etapas.

A primeira etapa consiste em um questionário para traçar um perfil e medir a racionalidade do respondente. O perfil consistia em indagar acerca de gênero; idade; curso de formação e período; religião e frequência de participação em cerimônias religiosas e; renda.

Para a racionalidade, optou-se por reproduzir o instrumento de coleta previamente validado no trabalho de Soares e Barbedo (2013). O referido trata-se de uma adequação para o cenário brasileiro do questionário originalmente proposto por Kahneman e Tversky (1979), previamente traduzida e modificada nos trabalhos de Kimura, Basso e Krauter (2006) e Silva et al. (2009). Trata-se de 13 questões de escolha binária "a" ou "b" que avaliam acerca do efeito certeza, nas questões de 1 a 8 , efeito reflexo, nas de 9 a 12 , e na $13^{\mathrm{a}}$ o efeito dos prospectos e o efeito isolamento nos respondentes (SOARES; BARBEDO, 2013). 
Nesta etapa, os respondentes seriam informados que não haveriam respostas certas ou erradas e que seu desempenho não seria avaliado e nem remunerado. Para o referido seria designado o tempo de resposta de 8 minutos. O questionário encontra-se reproduzido no Apêndice A.

A segunda etapa seria similar à tarefa das matrizes descrita no Desenho Original. Os voluntários receberiam as 20 matrizes matemáticas e seriam informados de que para cada matriz respondida corretamente, eles receberiam a importância de $\mathrm{R} \$ 0,50$. O tempo para solucionar todas as questões desta etapa seria de 5 minutos, similar ao proposto por Mazar, Amir e Ariely (2008). Entretanto, sem que os entrevistados tomassem conhecimento, as matrizes foram alteradas para que apenas a primeira delas tivesse um resposta matemática possível.

Decorrido o tempo de resposta, os voluntários seriam informados que deveriam contar quantas matrizes haviam resolvido e anotariam este número em uma ficha de cobrança, previamente fornecida, que seria entregue a outro fiscal que efetuaria o pagamento. Além disso, eles eram informados que seriam pagos com base no número escrito nesta ficha de cobrança e que antes de efetuarem o pagamento, deveriam rasgar e descartar o formulário contendo as matrizes.

Logo, os respondentes não teriam que apresentar as matrizes para que as mesmas fossem corrigidas. Com isto, esperava-se eliminar qualquer risco de detecção por parte dos voluntários e permitir que a desonestidade fosse praticada. Como só existiria uma matriz com resposta possível, qualquer resposta diferente de 1 pode ser entendida como desonestidade.

Em todos os casos, não seria permitido qualquer tipo de identificação dos voluntários durante o experimento, entretanto, no ato da entrega da ficha de cobrança, os alunos teriam que entregar também o Formulário 1 que o fiscal responsável pelo pagamento guardaria junto. No topo de cada um dos elementos do experimento haveria o nome do pesquisador e um número que seria similar à uma matrícula da instituição.

As matrizes, bem como as instruções para resolução das mesmas e a ficha de cobrança encontram-se ao final do texto nos Apêndice B e C, respetivamente. Além disso o roteiro do experimento está anexado no Apêndice D.

\subsection{DESCRIÇÃO DA AMOSTRA}


O estudo foi concentrado com alunos de graduação em da Universidade Federal do Rio Grande do Norte, que estejam cursando disciplinas dos cursos de Ciências Contábeis ou de Administração. A amostra foi delimitada a estes participantes por se entender que estes são ou serão agentes do mercado financeiro e de trabalho $\mathrm{O}$ universo de alunos dos cursos da instituição está composto por 1.566 pessoas, sendo 840 destas graduandos em Administração e 726 de Ciências Contábeis.

O experimento executado nos dias 02, 03 e 04 de fevereiro de 2016 em 5 turmas diferentes, atentando ao fato de não haver repetição de respondente e não sendo ultrapassado o limite de 30 participantes por sessão. O referido foi executado em sala de aula, durante o tempo cedido pelo professor da disciplina e sem que fosse feita qualquer intromissão por parte do mesmo. Não foi feita qualquer preferência por perfil de aluno havendo independência do percentual de créditos integralizados ou posição corrente no curso, idade ou inserção no mercado de trabalho. A amostra foi composta de 114 respostas válidas, sendo excluídos 2 casos onde o aluno não concluiu em tempo hábil o Formulário 1. As estatísticas descritivas serão apresentas no momento da discussão dos resultados.

\subsection{TRATAMENTO DOS DADOS}

O método de análise executado foi a análise de Regressão Linear Múltipla. Para tanto, os formulários foram inseridos em um software de tratamento estatístico. $\mathrm{O}$ modelo regressivo múltiplo baseou-se nas variáveis de efeito fixo estudadas no referencial teórico. Como variável dependente utilizou-se a Desonestidade Financeira observada no experimento supracitado. Como variáveis independentes: Racionalidade, Idade, Gênero, Renda, Curso de formação, Período, Religião e Assiduidade em cerimônias religiosas.

O modelo possui a seguinte descrição:

$$
\begin{aligned}
& \text { Des }=\beta_{1}+\beta_{2} \text { Rac }_{2}+\beta_{3} G_{3}+\beta_{4} I d_{4}+\beta_{5} \text { Ren }_{5} \\
& +\beta_{6} C_{6}+\beta_{7} \text { Per }_{7}+\beta_{8} \operatorname{Reg}_{8}+\beta_{9} A s_{9}+\varepsilon
\end{aligned}
$$

Onde:

Des $=$ Variável dependente de desonestidade financeira;

$\beta_{1}=$ Representa o intercepto ou constante de desonestidade;

$\beta_{2}, \beta_{3}, \beta_{4}, \beta_{5}, \beta_{6}, \beta_{7}, \beta_{8}$, e $\beta_{9}=$ Representam os coeficientes parciais de regressão de cada uma das variáveis do modelo; 
$R a c_{2}=$ Regressor de racionalidade;

$G n_{3}=$ Regressor de gênero;

$I d_{4}=$ Regressor de idade;

$\operatorname{Ren}_{5}=$ Regressor de renda;

$C_{6}=$ Regressor de curso de formação;

$\operatorname{Per}_{7}=$ Regressor de período atual do curso de graduação;

$\operatorname{Reg}_{8}=$ Regressor de religião;

$A s_{9}=$ Regressor de assiduidade de participação em cerimônias religiosas e;

$\varepsilon \quad=$ Termo de erro estocástico.

Para o presente modelo foram observados os pressupostos de Linearidade, Normalidade dos Resíduos, Ausência de Multicolinearidade, Especificação do Modelo e Homocedasticidade. Não foi feito teste para problemas de Autocorrelação, uma vez que em modelos de cortes transversais, tal pressupostos pode ser relaxado (GREENE, 2012).

O modelo regressivo baseia-se nos trabalhos discutidos no referencial teórico e nos objetivos geral e específicos do trabalho. A relação entre a desonestidade financeira, parte do pressuposto de Becker (1993) de que as atitudes desonestas dependem de fatores racionais de risco, retorno e probabilidade de deteç̧ão e da teoria da perspectiva de Kahneman e Tversky (1979) que trata de violações da teoria da utilidade esperada.

No que concerne ao gênero, as pesquisas de Conrads et al. (2013); Id. (2014); Houser, Vetter e Winter (2012); Azar, Yosef e Bar-Eli (2013); Dreber e Johanneson (2008); Friesen e Gangadharan (2013) trataram a questão de que indivíduos do sexo feminino tendem a ser mais honestas em relação aos dos sexo masculino. O referido foi considerado como relevante e por isto a variável foi inserida como controle para o modelo em questão.

De forma análoga, a idade também deve ser considerada como variável de controle, considerando a pesquisa de Conrads, et al. (2013) onde a idade seria capaz de influenciar negativamente a desonestidade e a de Friesen e Gangadharan (2013) que afirma o oposto.

Já a renda, apesar da literatura não trazer resultados conclusivos acerca de sua influência na desonestidade, achou-se necessário inserir a mesmas como variável de controle. Para o tratamento dos dados, as faixas de renda foram subdivididas em 5 
variáveis binárias dummy, uma vez que o referido não traria prejuízo de informações nem para o presente modelo regressivo.

No que concerne à religião Utikal e Fischbacher (2013) apresentaram relação positiva entre honestidade e religião, assim como o caso de Aveyard (2014) onde um lembrete moral religioso influencia de mesma forma. Logo a variável foi incluída. Entretanto, não foi feito controle experimental acerca de padrões religiosos. Em contrapartida foi incluída também uma variável de frequência de participação em cerimônias religiosas. O referido se deu por acreditar-se que e existem diferenças entre pessoas de mesma fé e de comportamentos diferentes de suas práticas religiosas. Por isto, foi incluída a variável de assiduidade em cerimônias religiosas.

Por fim, a formação dos indivíduos pode ter implicações sobre seus padrões de comportamento desonesto, apesar de as evidências na literatura apontarem apenas para graduandos na área de economia (LEWIS, et al. 2012. CHILDS, 2012. LUNDQUIST, et al. 2009). A amostra do presente estudo não abrange estudantes do referido curso, porém optou-se por inserir uma variável de controle para a graduação do respondente. Além disso, observou-se que em alguns cursos de graduação pode existir mudança de comportamento ao longo do mesmo. Seja pela influência do ambiente, pela presença de disciplinas relacionadas à ética profissional ou por outros fatores. Logo, foi inserida uma variável para o período do curso em questão, apesar de não ter sido feito controle sobre quais influências poderiam ser observadas.

Ainda tratando do período do curso em que o respondente se encontra, devido ao tamanho da amostra e pela distribuição irregular dos respondentes em determinados períodos, optou-se por dividi-los, transformando-os em variável dummy para análises futuras, em dois grupos: os iniciantes, que cursam até o quarto período (57 alunos) e os avançados que estão do quinto ao décimo (igualmente 57).

$\mathrm{Na}$ quinta parte deste trabalho, discutir-se-á os pressupostos da regressão, bem como as características descritivas da amostra além das implicações e resultados do presente modelo regressivo. 


\section{ANÁLISE DE DADOS}

\subsection{ESTATÍSTICA DESCRITIVA}

Dando início ao tratamento dos dados, a amostra, conforme anteriormente comentado, foi composta de 114 alunos de cursos de graduação da Universidade Federal do Rio Grande do Norte. Sobre os mesmos observa-se predominância do gênero feminino com 63 indivíduos e 51 do masculino. Quanto à idade, esta variou entre 17 e 43 anos, a média foi de aproximadamente 23 anos e com um desvio padrão de 4,77.

O curso de formação dos respondentes foi, em sua maioria, de Ciências Contábeis, com 88 observações. 23 respondentes cursavam Administração na universidade e 3 outros cursos. O período variou entre o segundo e o décimo, sem que fosse feita distinção entre o aluno que estava regular, ou seja, com a carga horária completa até o referido período, ou não. O detalhamento da distribuição dos alunos por período encontra-se no Quadro 2 abaixo.

Quanto à religião houve predominância do cristianismo, e o grupo foi subdividido em Católicos, Protestantes e Doutrina Espírita. Os números se subdividiram em 71 católicos, 19 protestante e 3 espíritas. Houveram também 19 que se declararam Ateus ou Agnósticos, e 2 de outras religiões. No que se refere à assiduidade em cerimônias religiosas, 20 afirmam nunca participar de tal, 34 dizem que vão raramente, 26 frequentam mensalmente e 34 semanalmente.

A renda foi indagada sob a forma de salários mínimos, sendo o grupo seguinte sempre o dobro do grupo anterior. 6 indivíduos afirmaram receber uma renda familiar média inferior a 1 salário mínimo e 14 estão entre 1 e 2 salários. Na faixa entre dois e quatro salários, foram observados 35 casos, faixa que corresponde à moda amostral. Houveram também 32 que afirmaram receber acima de 4 e menos que 8 salários; entre 8 e 16 salários, 20 respondentes e; acima de 16 salários mínimos apenas 7 voluntários.

No que concerne à racionalidade sob o prisma da Teoria da Perspectiva, conforme anteriormente dito, foi aplicado o questionário similar ao de Soares e Barbedo (2013). Para cada par de questões respondida de forma similar, por exemplo, as questões 1 e 2 respondidas igualmente, era atribuído o valor de 1, caso a resposta dos pares de questões fosse diferente, era atribuído o valor de 0 . Ao final, esses escores eram somados e divididos pelo total de pares de questões, obtendo-se assim um percentual de racionalidade por indivíduo. Sobre o mesmo, observou-se uma média para 
a amostra de 58\%, com uma variância de 6,22\%. O Quadro 2 abaixo apresenta o resumo dos descritivos da amostra.

Quadro 2 - Resumo dos Descritivos

\begin{tabular}{|c|c|c|c|c|c|c|c|}
\hline \multicolumn{2}{|l|}{ Gênero } & \multicolumn{2}{|l|}{ Idade } & \multicolumn{2}{|l|}{ Religião } & \multicolumn{2}{|l|}{ Assiduidade } \\
\hline \multirow{3}{*}{ Masculino } & \multirow{3}{*}{51} & Média & 22.92105 & Ateu & 19 & Nunca & 20 \\
\hline & & Desvio padrão & 4.774832 & Católicos & 71 & Raramente & 34 \\
\hline & & Variância & 22.79902 & Portestantes & 19 & Mensalmente & 26 \\
\hline \multirow[t]{2}{*}{ Feminino } & \multirow[t]{2}{*}{63} & Mínimo & 17 & Espirítas & 3 & \multirow[t]{2}{*}{ Semanalmente } & 34 \\
\hline & & Máximo & 43 & Outros & 2 & & \\
\hline \multicolumn{2}{|l|}{ Formação } & Período & & Renda & & \multicolumn{2}{|l|}{ Racionalidade } \\
\hline \multirow{4}{*}{ Contábeis } & \multirow{4}{*}{88} & Segundo & 1 & Até $1 \mathrm{Sal}$ & 6 & \multirow{2}{*}{ Média } & \multirow{2}{*}{0.580201} \\
\hline & & Terceiro & 28 & Entre 1 e 2 & 14 & & \\
\hline & & Quarto & 28 & Entre 2 e 4 & 35 & \multirow{2}{*}{ Mediana } & \multirow{2}{*}{0.571429} \\
\hline & & Quinto & 6 & Entre 4 e 8 & 32 & & \\
\hline \multirow[t]{3}{*}{ Administração } & \multirow[t]{3}{*}{23} & Sexto & 3 & Entre 8 e 16 & 20 & \multirow{2}{*}{ Moda } & \multirow{2}{*}{0.571429} \\
\hline & & Sétimo & 34 & Acima de 16 & 7 & & \\
\hline & & Oitavo & 11 & & & \multirow{2}{*}{ Desvio padrão } & \multirow[t]{2}{*}{0.24946} \\
\hline \multirow[t]{2}{*}{ Outros } & \multirow[t]{2}{*}{3} & Nono & 1 & & & & \\
\hline & & Décimo & 2 & & & Variância & 0.06223 \\
\hline
\end{tabular}

Fonte: Dados da pesquisa.

Por fim, a desonestidade financeira observada foi relativamente baixa. Considerando um cenário do experimento onde o risco de detecção da desonestidade sendo de 0 e sem uma punição explícita sendo informada. No referido, haviam 20 problemas a serem resolvidos e os participantes receberiam por resposta. Porém havia apenas 1 problema com possível solução.

Neste contexto, número máximo de matrizes supostamente resolvidas foi de 7 . Logo, a desonestidade dos indivíduos variou entre 0 e 6 . Apenas 35\% (40) dos voluntários mentiram no experimento, sendo 21 homens e 19 mulheres. Deste número, 18 fraudaram em uma resposta, 7 em duas, 8 em três, quatro respondentes receberam indevidamente por 4 matrizes, apenas um deles por 5 e duas pessoas para 6 respostas. $\mathrm{O}$ Gráfico 2 apresenta a distribuição do número de respostas desonestas do voluntários.

A priori, a média de desonestidade foi de 0,78 resposta por respondente, 2,26 levando em consideração somente os indivíduos que cometeram algum desvio. $\mathrm{O}$ número é considerado baixo, entretanto, quando comparado com pesquisas como a de Mazar, Amir e Ariely (2008), as médias de desonestidade foram parecidas. A grande diferença do apurado nesta pesquisa, reside no número baixo de respostas desonestas, onde nenhum respondente afirmou ter resolvido o número máximo possível de 19 
matrizes e o máximo de desonestidade observada foi de $31 \%$ do total possível. A média da desonestidade se situou entre $4 \%$, para o total da amostra, e $12 \%$, para o grupo que cometeu algum desvio.

Gráfico 2: Histograma de Distribuição da Desonestidade

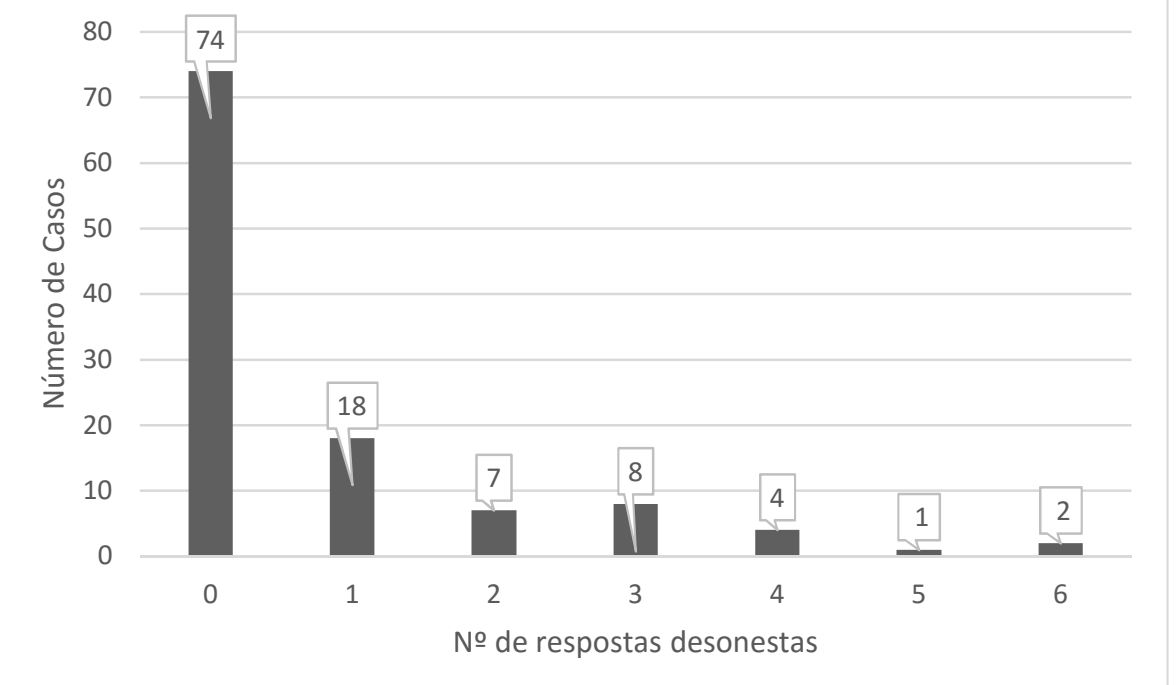

Fonte: dados da pesquisa

Acerca destes dados sobre desonestidade aparentemente não é possível fazer mais inferências sem o devido tratamento estatístico. O mesmo será discutido após os testes de especificação a seguir.

\subsection{TESTES DE ESPECIFICAÇÃO DO MODELO DE REGRESSÃO}

Conforme anteriormente discutido, a fim de se validar um modelo regressivo, faz-se necessária a não violação de alguns pressupostos, sendo eles: Linearidade, Normalidade dos Resíduos, Especificação do Modelo, Homocedasticidade, Ausência de Multicolinearidade e de Autocorrelação (GUJARATI; PORTER, 2011). Entretanto, a autocorrelação não se aplica em séries de corte transversal.

Para o Modelo Clássico de Regressão Linear, os parâmetros devem ser lineares, ou seja, mesmo que as variáveis não sejam lineares, os parâmetros de estimação e o erro aleatório devem ser inseridos de forma linear (GREENE, 2012. GUJARATI; PORTER, 2011) Para o presente modelo regressivo, todas as variáveis foram inseridas com seus parâmetros $\beta$ elevados a primeira potência. 
O pressuposto da distribuição normal dos resíduos é assumido em um modelo de regressão linear. Para tanto, foi feito o teste W de Shapiro-Wilk, obtendo-se um P-valor inferior a 1\%. Com isso, pode-se inferir que se rejeita a hipótese nula de não normalidade dos resíduos.

Porém, na visão de Greene (2012), a normalidade dos resíduos para análise de regressão linear múltipla não é necessária para a obtenção da maioria dos resultados. Além disso, de acordo com o Teorema do Limite Central, pode-se afirmar que aumentando o tamanho da amostra, obter-se-ia uma distribuição normal destes resíduos.

A pressuposição de multicolinearidade indica que quando duas ou mais variáveis independentes possuem alto valor de correlação, o modelo pode apresentar viés. Apesar de ser raro observar-se multicolinearidade igual a 0 , a questão é que estes valores não podem ser elevados (PAULO, 2007).

Quadro 3 - Fator de Inflação da Variância

\begin{tabular}{|l|r|r|}
\hline Variável & \multicolumn{1}{|l|}{ VIF } & \multicolumn{1}{l|}{ 1/VIF } \\
\hline Renda 0 & 1,80 & 0,554495 \\
Renda 1 & 2,90 & 0,344896 \\
Renda 2 & 4,39 & 0,22768 \\
Renda 3 & 4,16 & 0,240599 \\
Renda 4 & 3,48 & 0,287042 \\
Frequência & 1,51 & 0,661069 \\
Gênero & 1,40 & 0,713437 \\
Religião & 1,38 & 0,725462 \\
Curso & 1,33 & 0,749549 \\
Período & 1,31 & 0,76295 \\
Idade & 1,23 & 0,814734 \\
Racionalidade & 1,10 & 0,911479 \\
\hline
\end{tabular}

Fonte: Dados da pesquisa

Greene (2012) indica o teste do Fator de Inflação da Variância - VIF (Variance Inflation Factor), onde valores VIF acima de 10 ou seu inverso (1/VIF) próximos a 0 , indicam presença de multicolinearidade. Conforme pode-se observar no Quadro 3, os valores para todas as variáveis do modelo são aceitáveis.

No que concerne à especificação do modelo, Gujarati e Porter (2011) indicam o teste RESET de Ramsay (Regression Specification Error Test). O referido, teste para problemas de especificação, sem a necessidade de apresentação de um modelo regressivo alternativo. No presente estudo, foi apurado no teste um escore F de 1,80 e p- 
valor de 0,1515 , com isso, foi rejeitada a hipótese nula do teste para presença de variáveis omissas no modelo.

Quanto à homocedasticidade, Gujarati e Porter (2011) afirmam que a variância do termo de erro $\varepsilon$ deve ser a mesma, independente dos valores assumidos para X. Para testar esta hipótese, os mesmos autores recomendam o teste geral de heterocedasticidade de White e o de Breusch-Pagan-Godfrey. Uma vez efetuados os testes obtiveram-se valores do $\mathrm{X}^{2}(59,61261)$ acima do valor crítico a um nível de significância de 5\%. Além disso o p-valor $(0,8074)$ foi superior ao nível de significância, não rejeitando-se a hipótese nula do teste de homocedasticidade. No segundo teste, foi observado um $\mathrm{X}^{2}$ de 29,00 e um p-valor inferior a 0,00001. Isto indica que o modelo apresenta problemas de heterocedasticidade. O resumo dos dados dos testes de especificação, com exceção do VIF encontra-se no Quadro 4.

Quadro 4 - Resumo dos Testes de Especificação

\begin{tabular}{|l|l|l|r|}
\hline Teste & Pressuposto & Valor teste & p-valor \\
\hline Breusch-Pagan-Godfrey & \multicolumn{1}{|c|}{ Homocedasticidade } & $\mathrm{X}^{2}=29,00$ & 0,000 \\
White & & $\mathrm{X}^{2}=59,61$ & 0,8074 \\
Shapiro-Wilk W & Normalidade dos Resíduos & $\mathrm{W}=0,9128$ & 0,0000 \\
RESET de Ramsey & Variáveis omissas & $\mathrm{F}=1,80$ & 0,1514 \\
\hline
\end{tabular}

Fonte: Dados da pesquisa

Entretanto, foi feito o procedimento corretivo para o problema de heterocedasticidade, que é chamado de Correção Robusta de White ou padrões de correção para erros padrão robustos. O referido foi executado e o modelo regressivo gerado será discutido no sub tópico a seguir.

\subsection{ANÁLISE DO MODELO DE REGRESSÃO}

Passando a análise do poder preditivo do presente modelo regressivo para desonestidade financeira, após efetuados os testes e observados os pressupostos para regressão linear múltipla, o mesmo foi corrigido para erros padrões robustos através da metodologia de White. A estatística F de apresenta um valor de 2,25 a um nível de significância de $1 \%$. Isto indica que pode-se rejeitar a hipótese de que os coeficientes de regressão para todas as variáveis do modelo sejam iguais a zero.

Além disso, o $\mathrm{R}^{2}$ do modelo ajustado, apresenta um valor de 0,2641. Tal resultado pode ser interpretado como um percentual de $26,41 \%$ da variabilidade da 
amostra sendo explicada pelo modelo regressivo. Apesar do resultado não muito elevado, o mesmo já era esperado, uma vez que a desonestidade financeira, conforme comentado na introdução e referencial teórico deste trabalho, é função de fatores externos ao indivíduo (probabilidade de detecção e punição aplicável) e de causas intrínsecas (padrões éticos e custos psicológicos da mentira). O modelo em questão abordava somente os últimos fatores.

Outra possível interpretação dos resultados do $\mathrm{R}^{2}$ é de que as características individuais influenciam em $26 \%$, entretanto, uma vez alterados os fatores externos, pode haver mudança nos valores do presente modelo. O desenho experimental empregado foi de uma situação onde não havia qualquer probabilidade de detecção e nem uma possível sanção cabível para quem fosse descoberto fraudando. Caso algum dos cenários fosse inserido, o resultado do modelo poderia apresentar valores diferentes. O resumo dos testes característicos do modelo encontram-se no Quadro 5.

Passando para a análise da sensibilidade da desonestidade em relação às variáveis do modelo, percebe-se que apenas Racionalidade, Assiduidade e o Período em que se encontram os alunos foram estatisticamente significantes a 5\%. As demais variáveis foram consideradas como não relevantes, todavia, discutir-se-á seus resultados. Os coeficientes, erros padrão, estatística t e p-valores também estão expressos no Quadro 5.

A Racionalidade poderia apresentar 2 efeitos sobre a desonestidade financeira. Poderia um indivíduo mais racional, possuir uma percepção mais apurada sobre a situação e, baseados em seu senso de moralidade, deliberadamente inibir o impulso de desonestidade. A outra possibilidade seria a de que o respondente percebesse que não havia risco de detecção ou qualquer punição aplicável à fraude e tendesse a cometer mais desvios, maximizando seus interesses individuais.

Os resultados do presente estudo indicam quem a racionalidade influencia positivamente na desonestidade, ou seja, pessoas mais racionais tendem a ser menos honestas diante de um cenário livre de risco de detecção ou sanção aplicável. O coeficiente de regressão $\beta$ foi de 1,745 e o p-valor foi inferior a 0,001 , considerando um nível de significância de 1\%. Este resultado representa que para o recebimento indevido de cada resposta, o percentual de racionalidade do respondente tende a ser $1,745 \%$ maior.

Entretanto, mesmo a amostra contendo indivíduos que obtiveram um escore de $100 \%$ de racionalidade no instrumento de coleta de Kahneman e Tversky (1979), o 
número máximo de respostas indevidamente pagas ao respondente foi de 6 , quando se tinha a possibilidade de fraudar em 19. Tal fato poderia ser justificado pelo fato de no presente desenho experimental o número de resposta com resultado possível ser de apenas 1, e o voluntário deliberar acerca do um número muito alto de matrizes resolvidas levantar suspeitas e optar por um ganho inferior. Abeler, Becker e Falk (2014) afirmam que em uma situação onde só há uma alternativa para fraude, a desonestidade tende a diminuir. A possível justificativa é a de que caso haja só uma oportunidade o indivíduo se enxergue como $100 \%$ antiético e o custo interno da mentira aparente ser mais alto.

Quadro 5 - Regressão de Desonestidade Financeira

\begin{tabular}{|l|r|r|r|r|r|r|r|}
\hline \multicolumn{7}{|c|}{ Variável Dependente: Desonestidade Financeira } \\
\hline Independentes & \multicolumn{1}{|c|}{ Beta } & Erro Padrão & \multicolumn{1}{c|}{$\mathrm{T}$} & P-valor & $\mathrm{F}$ & P-valor & $\mathrm{R}^{2}$ \\
\hline Racionalidade & 1,745019 & 0,4496819 & 3,88 & 0,000 & & & \\
Curso & $-0,023466$ & 0,1581761 & $-0,15$ & 0,882 & & & \\
Frequência & $-0,382267$ & 0,1376397 & $-2,78$ & 0,007 & & & \\
Religião & 0,226986 & 0,1515828 & 1,50 & 0,137 & & & \\
Idade & $-0,029363$ & 0,0276178 & $-1,06$ & 0,290 & & & \\
Gênero & 0,016427 & 0,2732594 & 0,06 & 0,952 & & & \\
Periodo & $-0,625883$ & 0,2402371 & $-2,61$ & 0,011 & 2,52 & 0,006 & \multirow{2}{*}{0,2641} \\
Renda 0 & 0,347400 & 0,5347236 & 0,65 & 0,517 & & & \\
Renda 1 & 0,089204 & 0,5311703 & 0,17 & 0,867 & & & \\
Renda 2 & 0,790700 & 0,5496995 & 1,44 & 0,153 & & & \\
Renda 3 & 0,534384 & 0,477081 & 1,12 & 0,265 & & & \\
Renda 4 & 0,264265 & 0,5143287 & 0,51 & 0,609 & & & \\
Constante & 0,674014 & 0,9219864 & 0,73 & 0,466 & & & \\
\hline
\end{tabular}

Fonte: Dados da pesquisa

Os resultados da pesquisa foram diferentes do apurado nos trabalhos iniciais de Mazar e Ariely (2006) e Mazar, Amir e Ariely (2008), além da aplicação no cenário brasileiro de Santos (2010), que apuraram uma média de 2 respostas a mais do que o efetivamente resolvido. Além disso, pode-se observar que a média de matrizes resolvidas nos experimentos foi de 6 para os grupos de controle que não poderiam fraudar e de 8 para os que podiam. Uma fraude de aproximadamente $33 \%$ do total resolvido. No desenho experimental estudado, esse percentual foi de 78,07\%, considerando o número resolvido de 1 matriz correta e a desonestidade média de 0,78 , conforme anteriormente discutido. Mas considerando o percentual de desonestos obtêm- 
se um percentual próximo (40\%). Caso no experimento houvessem mais respostas corretas, espera-se uma desonestidade maior.

Contudo, outras variáveis também foram responsáveis pela variabilidade da desonestidade financeira. Quanto ao Curso de Graduação, os resultados não foram estatisticamente significantes. O referido corrobora com o discutido no referencial teórico. O trabalho de Houser, Vetter e Winter (2012), de forma similar, não apresentou diferença estatística para a área de formação e os Lundquist, et al. (2009), Lewis, et al. (2012) e Childs (2012) apresentaram apenas para alunos do curso de economia, que não compôs a amostra do presente estudo.

Entretanto, o presente modelo permitiu, mesmo que superficialmente, que fosse observados efeitos do ambiente institucional da universidade. A variável de Período, conforme anteriormente explicitado, foi transformada em binária, dividindo os alunos em iniciantes (0) e avançados (1). O coeficiente $\beta$ para a variável foi de $-0,625883$, significante a $5 \%(\mathrm{p}$-valor $=0,011)$. Isto é indicativo de que à medida que o aluno progride no curso, sua desonestidade tende a diminuir.

Tal fenômeno poderia ser um justificado pelo fato de que na vida universitária a responsabilidade individual tende a ser maior do que, por exemplo, na vida escolar. Outra interpretação possível é a de que em alguns programas de graduação, como o de ciências contábeis, existem componentes curriculares de ética profissional e a esta pode gerar influência positiva sobre o comportamento honesto. Uma terceira interpretação seria de que o ambiente organizacional da universidade tende a reprimir atitudes desonestas e, consequentemente, tornar o aluno mais honesto à medida que vai avançando na instituição. Entretanto, não fez parte do escopo do presente trabalho exercer qualquer tipo de controle sobre essas questões.

Todavia, o amadurecimento do aluno na instituição de ensino superior não apresentou relação, no presente estudo, com o envelhecimento cronológico do indivíduo. A variável de Idade, apesar de apresentar um $\beta$ igualmente negativo (0,029363), que indicaria um singela diminuição da desonestidade relacionada com o envelhecimento da pessoa, não foi estatisticamente significante, com um p-valor de 0,29. O referido corrobora com o apurado por Childs (2012); Franzen e Pointner (2013) e; Abeler, Becker e Falk (2014) e vai de encontro a Conrads, et al. (2013) e Friesen e Gangadharan (2013) que afirmaram haver influência negativa e positiva da idade sobre a desonestidade, respectivamente. 
Quanto ao Gênero, também não houve diferença estatisticamente significante para uma influência na desonestidade ( $\mathrm{p}$-valor $=0,952$ ). Este resultado já era esperado, considerando-se o volume de pesquisas que afirmam não haver distinção de sexo quanto aos padrões éticos (FRANZEN; POINTNER, 2013. ABELER; BECKER; FALK, 2014. LEWIS; et al, 2012. ROSENBAUM; et al, 2012. CAPPELEN; SØRENSEN; TUNGODDEN, 2013. CHILDS, 2012. ERAT; GNEEZY, 2012. GYLFASON; ARNARDOTTIR; KRISTINSSON, 2013. HOLM; KAWAGOE, 2010. LUNDQVIST; et al, 2009. GRAVERT, 2013).

A renda, conforme havia sido dito, dividiu os respondentes em grupos de acordo com a renda familiar média em salários mínimos, sendo cada grupo o dobro de salários do anterior, iniciando em 1 salário. Após os testes, não houve influência estatisticamente significante da renda sobre os de padrões de honestidade em nenhum dos grupos, conforme pode ser visto na coluna dos p-valores do Quadro 5. Tal resultado corrobora com o apurado por Franzen e Pointner (2013); Abeler, Becker e Falk (2014); Haan e Kooreman (2002) e; Childs (2012).

Uma inferência interessante sobre o resultado é o de que, dependendo do nível de renda do indivíduo o valor do dinheiro poderia ser diferente. Em um participante de renda familiar inferior a um salário mínimo esperava-se possuir um comportamento distinto diante da possibilidade de ganho de uma monta de $\mathrm{R} \$ 10,00$ em relação a um que perceba mais de 16 salários. Entretanto, conforme os dados da pesquisa indicam, e de certa forma, conforme a Teoria da Perspectiva (KAHNEMAN; TVERSKY, 1979), a decisão acerca do risco depende do ganho ou da perda e não da variação percentual da situação patrimonial.

Por fim, no tocante à Religião, não foi observada variação significativa, com um coeficiente de regressão $\beta$ de 0,226986 e um p-valor de 0,137. Este resultado condiz com o observado por Abeler, Becker e Falk (2014) e; Ruffle e Tobol (2014). Esta variável poderia exercer influência positiva ou negativa sobre a honestidade. Positiva, à medida que em todas as religiões que compuseram a amostra, há presença de um senso de justiça ou de uma divindade onisciente, onipresente e onipotente, em especial no cristianismo que prega a justiça divina e a recompensa dos jutos e honestos. Entretanto, Ariely (2012) afirma que existem indivíduos que se consideram corretos por praticarem atos bondosos exercendo sua fé e isto pode permitir uma margem de manobra mais flexível sobre a honestidade. 
Entretanto, a religião, ou ainda a ausência dela, pode representar um grupo muito heterogêneo entre si. Caso se considere o catolicismo, religião mais popular do Brasil, existem diferenças entre a forma que os cidadãos praticam sua fé. Por isto a inclusão de uma variável para a frequência de participação em cerimônias religiosas, uma vez que acredita-se que alguém em maior contato com doutrina religiosa pode apresentar comportamento diferente do que possui a mesma fé e hábitos diferentes.

A variável de Assiduidade em Cerimônias Religiosas apresentou um coeficiente de regressão de - 0,382267 , significante a 1\%. A variável foi inserida de forma nominal, mas pode-se observar que os indivíduos que frequentam mais regularmente algum tipo de missa ou culto, tendem a ser menos desonestos do que os que não o fazem com tanta frequência. Isto é indicativo de que um contato maior com sua fé, independente de qual seja ela, exerceria uma influência na honestidade que pode ser justificado pelo fato de a religião servir como uma bússola moral. Outra visão, reside no fato de acreditar que existe uma entidade superior observando e que aplicaria uma punição aos que cometem desvios. Entretanto, mais uma vez, não fez parte do objetivo deste trabalho investigar as possíveis causas do comportamento apresentado e não foram feitos controles para as causas destes efeitos. 


\section{CONSIDERAÇÕES FINAIS}

Grande parte dos problemas da nação podem ser atribuídos a problemas de corrupção motivados por ganhos financeiros de políticos, agentes públicos, servidores públicos e de empresários. Todavia, Ariely (2012) evidencia que a desonestidade não é específica de um grupo de indivíduos, a maioria dos mecanismos de controle que se utilizam nos dias de hoje não são para inibir um criminoso que possua os meios, mas sim para que as pessoas comuns se sintam inibidas de cometer desvios.

Conhecer quais mecanismos podem influenciar neste processo de ponderação para atitude desonesta, pode servir como fonte de informação para elaboração de políticas de controle mais eficazes. Outra perspectiva é a de que, a depender de características da população mais propensa a cometer desvios, pode-se aumentar o monitoramento sobre estes grupos.

Os achados desta pesquisa, quando comparados com os de outras, como a de Santos (2011), permitem inferir que com um menor número de tarefas realizadas corretamente tendem inibir a fraude. Como já foi discutido, é mais difícil para o indivíduo racional fraudar o dobro ou triplo do que foi efetivamente feito, em detrimento de o fazer quando este número cai para $1 / 4$ ou $1 / 3$ do realizado, similar ao apurado por Abeler, Becker e Falk (2014). Uma interpretação é a de que havendo melhor segregação de funções, onde o número de tarefas de responsabilidade de um funcionário seja menor, poderiam haver efeitos positivos sobre a honestidade. Entretanto, a depender do ambiente institucional, o efeito pode ser inverso, já que a responsabilização e, consequentemente, a culpabilidade poderiam diminuir e a desonestidade, por conseguinte, aumentar.

Além disso, controles acerca do ambiente, apesar de serem difíceis de serem implementados em um modelo experimental, poderiam ser feitos através de observações em voluntários presentes em ambientes mais fortes, com punições mais severas de pessoas corruptas, comparadas com o de ambientes mais fracos. Uma alternativa seria um experimento onde fosse apresentada uma possível punição para testar a influência disto na honestidade. Ou ainda a comparação dos dados de ambiente fraco, como os apurados na pesquisa, com o de grupos onde o ambiente fosse mais forte, como por exemplo os EUA, onde as punições são mais severas.

A questão de pesquisa se referia à relação entre a desonestidade financeira e à racionalidade sob o prisma da Teoria da Perspectiva. Sobre a mesma, foi observada uma 
relação positiva, indicando que quanto mais racional o indivíduo é mais desonesto ele tende a ser, considerando um cenário de baixo risco de detecção e a ausência de punição sobre o ato.

A questão da racionalidade apresenta-se como uma estrada de duas vias. Ao passo que indivíduos mais racionais, tendem a apresentar comportamento mais desonesto no cenário de baixa probabilidade de punição, os mesmos podem racionalizar que não podem apresentar ganhos altos em demasia para não levantar suspeitas. Pode-se observar pelo número máximo de respostas recebidas indevidamente (6) que existe um limite e que, mesmo sendo possível perceber um ganho maior, os indivíduos não vão até o fim. Tal fator, apresentou-se nas pesquisas discutidas na revisão da literatura: as pessoas tendem a ser desonestas, mas só até o ponto que isto não fere seus padrões éticos e sua autoimagem.

Outro dado interessante é de que aproximadamente $65 \%$ da amostra foi completamente honesta. Ou seja, quase dois terços da amostra não cederam à tentação de um ganho financeiro não merecido. Esta informação, entretanto, pode indicar que, existem indivíduos que não trapaceiam baseados na punição ou na chance de ser detectado. Apesar de que o mesmo não pode ser inferido acerca de outros tipos de desonestidade, por exemplo: acadêmica, conjugal ou ainda com valores mais substanciais para um mesmo cenário.

Quanto aos objetivos específicos, observou-se que o desenho experimental empregado no trabalho possuiu adesão com os participantes da amostra e foi possível observar a desonestidade financeira dos mesmos. Apenas dois indivíduos tiveram seus resultados descartados por não conseguirem resolver o Formulário 1 em tempo hábil e o número de alunos que preferiram deixar a sala de aula, uma vez anunciado o experimento, apesar de não terem sido contabilizados, foi relativamente baixo: aproximadamente 10 .

Quanto à presença de outras variáveis independentes que explicariam a fraude financeira, também foram obtidos resultados satisfatórios. $\mathrm{O} \mathrm{R}^{2}$ do modelo regressivo apresentou um valor de 0,2641 e não foi significante o resultado do teste realizado para variáveis omissas no modelo regressivo.

$\mathrm{O}$ fato de apenas a assiduidade em cerimônias e o período em que se encontra o aluno terem apresentado p-valores significativos a 5\% não justifica a exclusão das demais variáveis do modelo. É necessário levar-se em consideração que nas pesquisas relacionadas houveram diferentes metodologias de experimento e que resultados 
distintos podem ser obtidos para os efeitos das mesmas variáveis em cenários alternativos.

Apesar das limitações do presente estudo e das variáveis de efeito fixo que não apresentaram valores significativos, acredita-se que com os resultados obtidos na pesquisa tenha-se caminhado rumo a um melhor entendimento do tema. Com isto, o objetivo geral de investigar a relação entre as variáveis foi atingido.

O presente trabalho, possui como maiores limitações o tamanho da amostra e a falta de controle sobre algumas das variáveis apresentadas no tópico anterior. Talvez uma amostra contemplando maior variedade de cursos de graduação, assim como uma maior variabilidade de características individuais podem gerar resultados diferentes. Uma pesquisa que controle a influência da disciplina de ética profissional ou que investigue quais fatores do ambiente institucional influenciaram esta tendência queda na desonestidade ao longo da graduação do indivíduo complementaria os resultados desta pesquisa. Além disso, a idade assim como o período do curso do respondente apresentaram uma variância relativamente baixa.

Como recomendações para pesquisas futuras ressalta-se o aumento da amostra para que nos dados contenha maior amplitude quanto ao curso de graduação, idade, ou ainda um estudo comparativo entre instituições diferentes ou de alunos com profissionais de suas respectivas áreas. Uma outra perspectiva seria a de abordar estudantes de disciplinas de ética profissional e procurar fazer um estudo dos efeitos da disciplina no comportamento desonesto. Ressalte-se também que um experimento feito com quantias maiores de recursos financeiros por respondente poderia ser interessante, uma vez que podem haver variações acerca do montante a ser recebido com o ato desonesto.

Diante de tudo que foi discutido, torna-se evidente que o problema da desonestidade financeira deve ser tema de estudos posteriores. 


\section{REFERÊNCIAS}

ABELER, J.; BECKER, A.; FALK, A. Representative evidence on lying costs. Journal of Public Economics, v. 113, p. 96-104, 2014.

ABREU, M. C. S. de; MEIRELES, F. R. S.; CUNHA, L. T. da. Diferentes percepções sobre a responsabilidade social corporativa em empresas líderes do Brasil e da Índia. Internext, v. 10, n. 1, p. 18-29, 2015.

ARIELY, D. A Mais Pura Verdade Sobre a Desonestidade. Tradução de Leonardo Abramowicz. 1. ed. Rio de Janeiro: Elsevier, 2012.

ARROW, K. J. The economics of moral hazard: further comment. The American Economic Review, v. 58, n. 3, p. 537-539, 1968.

AVEYARD, M. E. A call to honesty: Extending religious priming of moral behavior to Middle Eastern Muslims. 2014.

AZAR, O. H.; YOSEF, S.; BAR-ELI, M. Do customers return excessive change in a restaurant?: A field experiment on dishonesty. Journal of Economic Behavior \& Organization. V. 93, p. 219-226, 2013.

BATESON, M.; NETTLE, D.; ROBERTS, G. Cues of being watched enhance cooperation in a real-world setting. Biology letters, v. 2, n. 3, p. 412-414, 2006.

BECKER, G. The Economic Way of Looking at Behavior. Journal of Political Economy. v101, 385-409, 1993.

BUCCIOL, Alessandro; PIOVESAN, Marco. Luck or cheating? A field experiment on honesty with children. Journal of Economic Psychology, v. 32, n. 1, p. 73-78, 2011.

BUSSELL, J. L. Why get technical? Corruption and the politics of public service reform in the Indian states. Comparative Political Studies, 2010.

CASTRO JÚNIOR, F. H. F.; FAMÁ, R. As novas finanças e a teoria comportamental no contexto da tomada de decisão sobre investimentos. Caderno de pesquisas em administração, São Paulo, v. 9, n. 2, abr./jun. 2002.

CAPPELEN, A. W.; SØRENSEN, E. Ø.; TUNGODDEN, B. When do we lie?. Journal of Economic Behavior \& Organization, v. 93, p. 258-265, 2013.

CHAIA, V.; TEIXEIRA, M. A. Democracia e escândalos políticos. São Paulo em Perspectiva, v. 15, n. 4, p. 62-75, 2001.

CHILDS, J. Gender differences in lying. Economics Letters, v. 114, n. 2, p. 147-149, 2012.

COHEN, T. R. et al. Do groups lie more than individuals? Honesty and deception as a function of strategic self-interest. Journal of Experimental Social Psychology, v. 45, n. 6, p. 1321-1324, 2009.

CONRADS, J. et al. Lying and team incentives. Journal of Economic Psychology, v. 34, p. 1-7, 2013.

CONRADS, J. et al. Honesty in tournaments. Economics Letters, v. 123, n. 1, p. 90-93, 2014.

DA ROSA, M. M. et al. A Lei de Acesso à Informação como instrumento de controle social: diagnóstico dos municípios do sul do Brasil à luz do artigo $8^{\circ}$ da lei 12527/2011. Navus-Revista de Gestão e Tecnologia, v. 6, n. 1, p. 72-87, 2015. 
DAVIS, S. F. et al. Academic dishonesty: Prevalence, determinants, techniques, and punishments. Teaching of Psychology, v. 19, n. 1, p. 16-20, 1992.

DREBER, A.; JOHANNESSON, M. Gender differences in deception.Economics Letters, v. 99, n. 1, p. 197-199, 2008.

ERAT, S. Avoiding lying: The case of delegated deception. Journal of Economic Behavior \& Organization. V. 93, p. 273-278, 2013.

; GNEEZY, U. White lies. Management Science, v. 58, n. 4, p. 723-733, 2012.

FERREIRA, V. R. de M. Psicologia econômica: estudo do comportamento econômico e da tomada de decisão. Rio de Janeiro: Elsevier, 2008.

FRANZEN, A.; POINTNER, S. The external validity of giving in the dictator game. Experimental Economics, v. 16, n. 2, p. 155-169, 2013.

FRIESEN, L.; GANGADHARAN, L. Designing self-reporting regimes to encourage truth telling: An experimental study. Journal of Economic Behavior \& Organization, v. 94, p. 90-102, 2013.

GAMLIEL, E.; PEER, E. Explicit risk of getting caught does not affect unethical behavior. Journal of Applied Social Psychology, v. 43, n. 6, p. 1281-1288, 2013.

GARRISON, R. H.; NOREEN, E. W; BREWER, P. C. Contabilidade Gerencial. Tradução de Antonio Zoratto Sanvicente. 11. ed. Rio de Janeiro: LTC, 2007.

GIBSON, R.; TANNER, C.; WAGNER, A. F. Preferences for truthfulness: Heterogeneity among and within individuals. American Economic Review, v. 103, p. 532-548, 2013.

GIL, Antonio Carlos. Como elaborar projetos de pesquisa. 6. ed. São Paulo: Atlas, 2008.

GINO, F.; AYAL, S.; ARIELY, D. Self-serving altruism? The lure of unethical actions that benefit others. Journal of economic behavior \& organization, v. 93, p. 285-292, 2013.

; WILTERMUTH, S. S. Evil genius? How dishonesty can lead to greater creativity. Psychological science, p. 0956797614520714, 2013.

GLOVER, S. H. et al. Re-examining the influence of individual values on ethical decision making. In: From the Universities to the Marketplace: The Business Ethics Journey. Netherlands: Springer, 1997.

GNEEZY, U. Deception: The role of consequences. American Economic Review, p. 384-394, 2005.

GRAVERT, C. How luck and performance affect stealing. Journal of Economic Behavior \& Organization, v. 93, p. 301-304, 2013.

GREENE, W. H. Econometric analysis. 7th ed. Boston: Prentice Hall, 2012.

GRIMES, P. W. Dishonesty in Academics and Business: A Cross-Cultural Evaluation of Students Attitudes. Journal of Business Ethics. 49: 273-290. 2004.

GUJARATI, D. N.; PORTER, D. C. Econometria Básica 5 ed. AMGH Editora, 2011.

GYLFASON, H. F.; ARNARDOTTIR, A. A.; KRISTINSSON, K. More on gender differences in lying. Economics Letters, v. 119, n. 1, p. 94-96, 2013. 
HALFELD, M.; TORRES, F. de F. L. Finanças comportamentais: a aplicações no contexto brasileiro. Revista de administração de empresas, v. 41, n. 2, p. 64-71, 2001.

HAAN, M.; KOOREMAN, P. Free riding and the provision of candy bars. Journal of Public Economics, v. 83, n. 2, p. 277-291, 2002.

HENDRIKSEN, E. S.; VAN BREDA, M, F. Teoria da contabilidade. Tradução da 5. ed. americana por Antonio Zoratto Sanvicente. São Paulo: Atlas, 1999

HEIDENHEIMER. A. J. Perspectives in the perception of corruption. In: HEIDENHEIMER, A. J. Political corruption: readings in comparative analysis. New York: Hold, Rinehart and Wilston. pp.18-28, 1970.

HOLLINGER, R. C.; LANZA-KADUCE, L. Academic dishonesty and the perceived effectiveness of countermeasures: An empirical survey of cheating at a major public university. NASPA journal, v. 33, n. 4, p. 292-306, 1996.

HOLM, H. J.; KAWAGOE, T. Face-to-face lying-An experimental study in Sweden and Japan. Journal of Economic Psychology, v. 31, n. 3, p. 310-321, 2010.

HOUSER, D.; VETTER, S.; WINTER, J. Fairness and cheating. European Economic Review, v. 56, n. 8, p. 1645-1655, 2012.

JENSEN, M. C. Paying People to Lie: The Truth aboutthe Budgeting Process. European Financial Management, v. 9, n. 3, p. 379-406, 2003

. MECKLING, W. H. Theory of the firm: Managerial behavior, agency costs and ownership structure. Journal of financial economics, v. 3, n. 4, p. 305-360, 1976.

JENSEN, L. A. et al. It's wrong, but everybody does it: Academic dishonesty among high school and college students. Contemporary Educational Psychology, v. 27, n. 2, p. 209-228, 2002.

KAHNEMAN, D. TVERSKY, A. Judgment under uncertainty: Heuristics and biases. Science, v. 185, n. 4157, p. 1124-1131, 1974.

. Prospect theory: an analysis of decisions under risk. Econometrica, v. 47, n. 2, p. 263-291, 1979.

Choices, values, and frames. American psychologist, v. 39, n. 4, p. 341, 1984.

KEIZER, K.; LINDENBERG, S.; STEG, L. The spreading of disorder. Science, v. 322 , n. 5908, p. 1681-1685, 2008.

KIMURA, H.; BASSO, L. F. C.; KRAUTER, E. Paradoxos em Finanças: teoria moderna versus finanças comportamentais. Revista de Administração de Empresas, v. 46, n. 1, p. 41-58, 2006.

LEVENSON, H. Multidimensional Locus of Control in psychiatric patients. Journal of Consulting and Clinical Psychology, V. 41, p. 397-404. 1973.

LEWIS, A. et al. Drawing the line somewhere: An experimental study of moral compromise. Journal of Economic Psychology, v. 33, n. 4, p. 718-725, 2012.

LOWEN, A. O corpo em terapia: a abordagem bioenergética. São Paulo. Summus. 1977.

LUNDQUIST, T. et al. The aversion to lying. Journal of Economic Behavior \& Organization, v. 70, n. 1, p. 81-92, 2009. 
MCKENZIE, S. Driven to Cheat: A Study on the Drivers of Dishonesty - through the Game of Golf. 2009.

MARCONI, M. de A.; LAKATOS, E. M. Técnicas de pesquisa, planejamento e execução de pesquisa. São Paulo: Atlas, 1999.

MATOS, N. B. Governança Eletrônica Municipal E Eficiência Na Distribuição De Recursos Públicos: Uma análise nos municípios mais populosos do Brasil. 2015. 76 f. Dissertação (Mestrado em Ciências Contábeis) - Programa Multiinstitucional e Interregional de Pós-Graduação em Ciências Contábeis da Universidade de Brasília, Universidade Federal da Paraíba e Universidade Federal do Rio Grande do Norte, Natal. 2015.

MAZAR, N.; AMIR, O.; ARIELY, D. The dishonesty of honest people: A theory of self-concept maintenance. Journal of marketing research, v. 45, n. 6, p. 633-644, 2008 .

ARIELY, D. Dishonesty in everyday life and its policy implications. Journal of Public Policy \& Marketing, v. 25, n. 1, p. 117-126, 2006.

MEAD, N. L. et al. Too tired to tell the truth: Self-control resource depletion and dishonesty. Journal of Experimental Social Psychology. V. 45, p. 594-597, 2009.

MELO, C. L. L. de. DETERMINANTES DA AVERSÃO À PERDA EM DECISÕES FINANCEIRAS: uma investigação por meio de modelos de equações estruturais. 2014. 199 f. Tese (Doutorado em Ciências Contábeis) - Programa Multiinstitucional e Interregional de Pós-Graduação em Ciências Contábeis da Universidade de Brasília, Universidade Federal da Paraíba e Universidade Federal do Rio Grande do Norte, Natal. 2014.

MULLEN, E.; NADLER, J. Moral spillovers: The effect of moral violations on deviant behavior. Journal of Experimental Social Psychology, v. 44, n. 5, p. 1239-1245, 2008.

NAGIN, D. S.; POGARSKY, G. Experimental Investigation of Deterrence: Cheating, Self-Serving Bias, and Impulsivity, An. Criminology, v. 41, p. 167, 2003.

NAQUIN, C. E.; KURTZBERG, T. R.; BELKIN, L. Y. The finer points of lying online: e-mail versus pen and paper. Journal of Applied Psychology, v. 95, n. 2, p. 387, 2010.

OKEKE, E. N.; GODLONTON, S. Doing wrong to do right? Social preferences and dishonest behavior. Journal of Economic Behavior \& Organization. V. 106, p. 124$139,2014$.

PAULO, E. Manipulação das informações contábeis: uma análise teórica e empírica sobre os modelos operacionais de detecção de gerenciamento de resultados. 2007. Tese de Doutorado. Universidade de São Paulo.

PINA, V.; TORRES, L.; ACERETE, B. Are ICTs promoting government accountability?: A comparative analysis of e-governance developments in 19 OECD countries. Critical Perspectives on Accounting, v. 18, n. 5, p. 583-602, 2007.

RAUPP, F. M.; BEUREN, I. M. Metodologia da pesquisa aplicável às ciências sociais. In: BEUREN, Ilse Maria (Org.). Como elaborar trabalhos monográficos em contabilidade: teoria e prática. São Paulo: Atlas, 2003.

REPPOLD, C. T.; HUTZ, C. S. Reflexão social, controle percebido e motivações à adoção: características psicossociais das mães adotivas. Estudos Psicologia, 8(1), 2536. 2003. 
ROCHA, Z. J. Os Tribunais de Contas e os desafios para promoção do controle social. Revista TCMRJ, Rio de Janeiro, n. 46, p. 4-11, 2011.

RODRIGUES, D. M. Os aspectos cognitivos da qualidade de vida: Um estudo entre as variáveis do locus de controle e as do bem-estar subjetivo. Tese de Doutorado. Universidade Federal do Rio de Janeiro, Rio de Janeiro. 2007.

RUFFLE, B. J.; TOBOL, Y. Honest on Mondays: Honesty and the temporal separation between decisions and payoffs. European Economic Review, v. 65, p. 126-135, 2014.

ROSENBAUM, S. M. et al. Market economies and pro-social behavior: Experimental evidence from Central Asia. The Journal of Socio-Economics, v. 41, n. 1, p. 64-71, 2012.

M.; BILLINGER, S.; STIEGLITZ, N. Let's be honest: A review of experimental evidence of honesty and truth-telling. Journal of Economic Psychology, v. 45, p. 181-196, 2014.

ROTTER, J. B. Generalized expectancies for internal versus external control of reinforcement. Psychological Monographs, 80, Washington. 1966.

SÁ, A. L. de. Teoria da Contabilidade. São Paulo: Atlas, 2006

SANTOS, P. F. dos. A DESONESTIDADE DE PESSOAS HONESTAS UM EXPERIMENTO NO BRASIL. 2011. 97 f. Dissertação (Mestrado em Economia) Programa de Pós-Graduação em Economia da Universidade de Brasília, Brasília. 2011.

SILVA, R. F. M.; et al. Finanças comportamentais: um estudo comparativo utilizando a teoria dos perspectivas com os alunos de graduação do curso de Ciências Contábeis. Revista Brasileira de Gestão de Negócios, v. 11, n. 33, p. 383-403, 2009.

SKINNER, E. A. Perceived control, motivation and coping. London: Sage Publications, 1995.

; CHAPMAN, Michael; BALTES, Paul B. Control, means-ends, and agency beliefs: a new conceptualization and its measurement during childhood. Journal of Personality and Social Psychology, v. 54, n. 1, p. 117, 1988.

SOARES, H. F. G.; BARBEDO, C. H. da S. Desempenho Acadêmico e a Teoria do Prospecto: Estudo Empírico sobre o Comportamento Decisório. RAC-Revista de Administração Contemporânea, v. 17, n. 1, p. 64-82, 2013.

SODRÉ, A. C. de A.; ALVES, M. F. C. Relação entre emendas parlamentares e corrupção municipal no Brasil: estudo dos relatórios do programa de fiscalização da Controladoria-Geral da União. RAC-Revista de Administração Contemporânea, v. 14, n. 3, p. 414-433, 2010.

SUTTER, M. Deception through telling the truth?! experimental evidence from individuals and teams*. The Economic Journal, v. 119, n. 534, p. 47-60, 2009.

TAVEIRA, L. D. B. Controle Percebido, Desempenho Acadêmico E Racionalidade: Um estudo à luz da teoria da perspectiva com estudantes de Ciências Contábeis na UFRN. 2014. 89 f. Dissertação (Mestrado em Ciências Contábeis) - Programa Multiinstitucional e Inter-regional de Pós-Graduação em Ciências Contábeis da Universidade de Brasília, Universidade Federal da Paraíba e Universidade Federal do Rio Grande do Norte, Natal. 2014.

UTIKAL, V.; FISCHBACHER, U. Disadvantageous lies in individual decisions. Journal of Economic Behavior \& Organization, v. 85, p. 108-111, 2013. 
ZHONG, C.; BOHNS, V. K.; GINO, F. Good lamps are the best police darkness increases dishonesty and self-interested behavior. Psychological Science, v. 21, n. 3, p. 311-314, 2010. 
APÊNDICES 
APÊNDICE A - QUESTIONÁRIO SOBRE A RACIONALIDADE À LUZ DA TEORIA DA PERSPECTIVA

Responsável: Agamenon da Costa Melo Segundo - Matrícula: 14/068515

\section{Perfil do Respondente}

1 - Gênero:

( ) Masculino

( ) Feminino

2 - Idade: anos.

3 - Período/Curso de Formação:

4 - Religião:

5 - Frequência de participação em cerimônias religiosas:

( ) Nunca

( ) Raramente

( ) Mensalmente

( ) Semanalmente

6 - Renda familiar média:

( ) Até R\$788,00

( ) Entre R\$ 788,00 e R\$ 1.576,00

( ) Entre R\$1.576,00 e R \$ 3.152,00

( ) Entre R\$3.152,00 e R\$6.304,00

( ) Entre R\$ 6.304,00 e R\$12.608,00

( ) Acima de R\$12.608,00 
Leia e escolha apenas uma alternativa. Este bloco apresenta questões envolvendo escolhas sobre preferências das pessoas, logo, não existem respostas corretas ou incorretas.

\section{Problema 1: Qual é a alternativa que representa sua escolha?}

( ) Alternativa A

$33 \%$ de chances de ganhar $\$ 2500$

$66 \%$ de chances de ganhar $\$ 2400$

$1 \%$ de chances de ganhar $\$ 0$
( ) Alternativa B

$100 \%$ de chances de ganhar $\$ 2400$

\section{Problema 2: Qual é a alternativa que representa sua escolha?}

( ) Alternativa A

$33 \%$ de chances de ganhar $\$ 2500$

$67 \%$ de chances de ganhar $\$ 0$
( ) Alternativa B

$34 \%$ de chances de ganhar $\$ 2400$

$66 \%$ de chances de ganhar $\$ 0$

Problema 3: Qual é a alternativa que representa sua escolha?

( ) Alternativa A

$80 \%$ de chances de ganhar $\$ 4000$

$20 \%$ de chances de ganhar $\$ 0$
( )Alternativa B

$100 \%$ de chances de ganhar $\$ 3000$

Problema 4: Qual é a alternativa que representa sua escolha?

( ) Alternativa A

$20 \%$ de chances de ganhar $\$ 4000$

$80 \%$ de chances de ganhar $\$ 0$
( ) Alternativa B

$25 \%$ de chances de ganhar $\$ 3000$

$75 \%$ de chances de ganhar $\$ 0$

\section{Problema 5: Qual é a alternativa que representa sua escolha?}

( ) Alternativa A

$50 \%$ de chances de ganhar uma viagem de três semanas para a Inglaterra, França e Itália Inglaterra

$50 \%$ de chances de não ganhar nada

\section{( ) Alternativa B}

$100 \%$ de chances de ganhar uma viagem de uma semana para

\section{Problema 6: Qual é a alternativa que representa sua escolha?}

\section{( ) Alternativa A}

$5 \%$ de chances de ganhar uma viagem de três semanas para a Inglaterra, França e Itália Inglaterra

95\% de chances de não ganhar nada

\section{( ) Alternativa B}

$10 \%$ de chances de ganhar uma viagem de uma semana para

$90 \%$ de chances de não ganhar nada 


\section{Problema 7: Qual é a alternativa que representa sua escolha?}

( ) Alternativa A

$45 \%$ de chances de ganhar $\$ 6000$

$55 \%$ de chances de ganhar $\$ 0$
( ) Alternativa B

$90 \%$ de chances de ganhar $\$ 3000$

$10 \%$ de chances de ganhar $\$ 0$

Problema 8: Qual é a alternativa que representa sua escolha?

( ) Alternativa A

$0,1 \%$ de chances de ganhar $\$ 6000$

$99,9 \%$ de chances de ganhar $\$ 0$
( ) Alternativa B

$0,2 \%$ de chances de ganhar $\$ 3000$

$99,8 \%$ de chances de ganhar $\$ 0$

\section{Problema 9: Qual é a alternativa que representa sua escolha?}

\section{( ) Alternativa A}

$80 \%$ de chances de perder $\$ 4000$

$20 \%$ de chances de perder $\$ 0$
( ) Alternativa B

$100 \%$ de chances de perder $\$ 3000$

Problema 10: Qual é a alternativa que representa sua escolha?

( ) Alternativa A

$20 \%$ de chances de perder $\$ 4000$

$80 \%$ de chances de perder $\$ 0$
( ) Alternativa B

$25 \%$ de chances de perder $\$ 3000$

$75 \%$ de chances de perder $\$ 0$

\section{Problema 11: Qual é a alternativa que representa sua escolha?}

( ) Alternativa A

$45 \%$ de chances de perder $\$ 6000$

$55 \%$ de chances de perder $\$ 0$
( ) Alternativa B

$90 \%$ de chances de perder $\$ 3000$

$10 \%$ de chances de perder $\$ 0$

Problema 12: Qual é a alternativa que representa sua escolha?

\section{( ) Alternativa A}

$0,1 \%$ de chances de perder $\$ 6000$

$99,9 \%$ de chances de perder $\$ 0$
( ) Alternativa B

$0,2 \%$ de chances de perder $\$ 3000$

$99,8 \%$ de chances de perder $\$ 0$

Problema 13: Considere um jogo de dois estágios. No primeiro estágio, existe uma probabilidade de $75 \%$ de que o jogo termine sem que você ganhe nada, e uma probabilidade de $25 \%$ de que se mova ao segundo estágio. Se você atingir o segundo estágio, você pode escolher entre as alternativas a seguir. Observe que a escolha deve ser feita antes do início do jogo.

( ) Alternativa A

$80 \%$ de chances de ganhar $\$ 4000$

$20 \%$ de chances de ganhar $\$ 0$
( ) Alternativa B

$100 \%$ de chances de ganhar $\$ 3000$ 
APÊNDICE B - MATRIZES MATEMÁTICAS

PROGRAMA MULTIINSTITUCIONAL E INTER-REGIONAL DE PÓSGRADUAÇÃO EM CIÊNCIAS CONTÁBEIS UNB/UFPB/UFRN.

Responsável: Agamenon da Costa Melo Segundo - Matrícula: 14/068515

\section{Parte II - Matrizes Matemáticas}

Em cada uma das vinte (20) tabelas, circule os dois (2) únicos números cuja soma é exatamente igual a dez (10)

Matriz 1

\begin{tabular}{|l|l|l|}
\hline 4,70 & 6,40 & 5,30 \\
\hline 1,69 & 4,55 & 9,31 \\
\hline 8,98 & 4,99 & 8,59 \\
\hline 5,70 & 2,14 & 3,18 \\
\hline
\end{tabular}

Matriz 2

\begin{tabular}{|l|l|l|}
\hline 7,09 & 3,47 & 1,00 \\
\hline 3,96 & 1,78 & 0,24 \\
\hline 4,79 & 8,56 & 2,65 \\
\hline 1,57 & 2,22 & 1,49 \\
\hline
\end{tabular}

Matriz 3

\begin{tabular}{|l|l|l|}
\hline 0,13 & 0,83 & 7,55 \\
\hline 3,14 & 5,87 & 1,95 \\
\hline 4,65 & 8,71 & 4,75 \\
\hline 4,45 & 4,28 & 3,62 \\
\hline
\end{tabular}

Matriz 4

\begin{tabular}{|l|l|l|}
\hline 3,45 & 1,38 & 1,25 \\
\hline 0,18 & 3,99 & 0,28 \\
\hline 8,97 & 8,82 & 3,02 \\
\hline 3,93 & 9,42 & 9,61 \\
\hline
\end{tabular}

Matriz 5

\begin{tabular}{|l|l|l|}
\hline 4,74 & 4,29 & 5,99 \\
\hline 2,19 & 1,91 & 1,75 \\
\hline 7,48 & 5,87 & 8,80 \\
\hline 9,81 & 8,69 & 4,19 \\
\hline
\end{tabular}

Matriz 6

\begin{tabular}{|l|l|l|}
\hline 2,96 & 4,83 & 8,47 \\
\hline 4,67 & 7,54 & 0,84 \\
\hline 4,50 & 9,75 & 2,97 \\
\hline 4,25 & 6,95 & 7,47 \\
\hline
\end{tabular}


Matriz 7

\begin{tabular}{|l|l|l|}
\hline 2,75 & 3,49 & 8,53 \\
\hline 0,95 & 1,48 & 9,88 \\
\hline 4,93 & 6,46 & 9,65 \\
\hline 9,78 & 9,38 & 5,34 \\
\hline
\end{tabular}

Matriz 8

\begin{tabular}{|l|l|l|}
\hline 4,53 & 6,74 & 7,27 \\
\hline 9,16 & 2,21 & 8,55 \\
\hline 3,92 & 3,36 & 3,14 \\
\hline 2,53 & 9,35 & 0,41 \\
\hline
\end{tabular}

Matriz 9

\begin{tabular}{|l|l|l|}
\hline 8,09 & 6,46 & 6,61 \\
\hline 5,24 & 6,09 & 1,96 \\
\hline 1,84 & 0,70 & 7,09 \\
\hline 0,01 & 2,98 & 7,78 \\
\hline
\end{tabular}

Matriz 10

\begin{tabular}{|l|l|l|}
\hline 2,84 & 7,56 & 6,60 \\
\hline 3,86 & 9,28 & 2,95 \\
\hline 1,13 & 9,73 & 2,78 \\
\hline 0,83 & 6,03 & 9,98 \\
\hline
\end{tabular}

Matriz 11

\begin{tabular}{|l|l|l|}
\hline 8,82 & 4,27 & 9,85 \\
\hline 9,71 & 4,80 & 3,78 \\
\hline 5,52 & 7,79 & 4,72 \\
\hline 1,34 & 5,55 & 1,15 \\
\hline
\end{tabular}

Matriz 12

\begin{tabular}{|l|l|l|}
\hline 0,36 & 1,99 & 6,48 \\
\hline 6,01 & 5,16 & 3,39 \\
\hline 9,74 & 2,82 & 4,58 \\
\hline 2,00 & 9,19 & 3,26 \\
\hline
\end{tabular}

Matriz 13

\begin{tabular}{|l|l|l|}
\hline 3,67 & 3,39 & 5,33 \\
\hline 0,49 & 9,22 & 4,54 \\
\hline 6,46 & 0,17 & 1,08 \\
\hline 3,03 & 5,72 & 2,98 \\
\hline
\end{tabular}

Matriz 14

\begin{tabular}{|l|l|l|}
\hline 4,49 & 4,56 & 6,73 \\
\hline 5,30 & 2,27 & 5,34 \\
\hline 2,88 & 0,77 & 6,40 \\
\hline 2,74 & 3,64 & 9,34 \\
\hline
\end{tabular}


Matriz 15

\begin{tabular}{|l|l|l|}
\hline 2,72 & 8,79 & 0,81 \\
\hline 6,13 & 6,02 & 3,18 \\
\hline 6,52 & 1,03 & 8,95 \\
\hline 2,28 & 3,61 & 7,72 \\
\hline
\end{tabular}

Matriz 16

\begin{tabular}{|l|l|l|}
\hline 7,77 & 9,10 & 3,94 \\
\hline 7,44 & 7,91 & 8,51 \\
\hline 9,59 & 6,96 & 0,99 \\
\hline 6,53 & 4,06 & 6,61 \\
\hline
\end{tabular}

Matriz 17

\begin{tabular}{|l|l|l|}
\hline 6,50 & 3,62 & 0,31 \\
\hline 3,60 & 6,19 & 5,92 \\
\hline 2,83 & 0,65 & 6,13 \\
\hline 9,12 & 0,38 & 6,17 \\
\hline
\end{tabular}

Matriz 18

\begin{tabular}{|c|c|c|}
\hline 2,98 & 4,02 & 3,97 \\
\hline 4,80 & 1,62 & 4,65 \\
\hline 5,89 & 7,85 & 7,70 \\
\hline 4,34 & 9,97 & 2,46 \\
\hline
\end{tabular}

Matriz 19

\begin{tabular}{|l|l|l|}
\hline 3,83 & 4,83 & 8,74 \\
\hline 8,24 & 5,92 & 6,37 \\
\hline 6,63 & 4,40 & 1,87 \\
\hline 0,62 & 6,78 & 1,43 \\
\hline
\end{tabular}

Matriz 20

\begin{tabular}{|l|l|l|}
\hline 3,16 & 9,76 & 8,33 \\
\hline 8,70 & 3,80 & 6,36 \\
\hline 2,67 & 8,20 & 2,40 \\
\hline 8,27 & 6,18 & 0,10 \\
\hline
\end{tabular}


APÊNDICE C - FICHA DE COBRANÇA

PROGRAMA MULTIINSTITUCIONAL E INTER-REGIONAL DE PÓSGRADUAÇÃO EM CIÊNCIAS CONTÁBEIS UNB/UFPB/UFRN.

Responsável: Agamenon da Costa Melo Segundo - Matrícula: 14/068515

FICHA DE COBRANÇA

NÚMERO DE MATRIZES RESOLVIDAS:

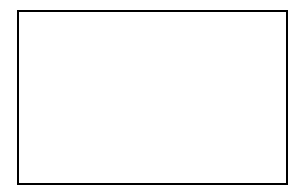

PROGRAMA MULTIINSTITUCIONAL E INTER-REGIONAL DE PÓSGRADUAÇÃO EM CIÊNCIAS CONTÁBEIS UNB/UFPB/UFRN.

Responsável: Agamenon da Costa Melo Segundo - Matrícula: 14/068515

FICHA DE COBRANÇA

NÚMERO DE MATRIZES RESOLVIDAS:

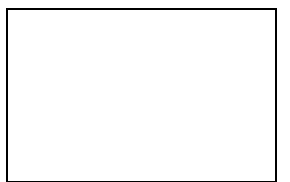

PROGRAMA MULTIINSTITUCIONAL E INTER-REGIONAL DE PÓSGRADUAÇÃO EM CIÊNCIAS CONTÁBEIS UNB/UFPB/UFRN.

Responsável: Agamenon da Costa Melo Segundo - Matrícula: 14/068515

FICHA DE COBRANÇA

NÚMERO DE MATRIZES RESOLVIDAS: 


\section{APÊNDICE D - ROTEIRO DO EXPERIMENTO}

Responsável: Agamenon da Costa Melo Segundo

Assistente de Pesquisa: Sylvia Galvão Vasconcelos Pinheiro

Local: Universidade Federal do Rio Grande do Norte, Campus Central. Av. Sen. Salgado Filho S/N.

Data: 02/02/2016, 03/02/2016 e 04/02/2016

Horário: $10 \mathrm{~h}-22 \mathrm{~h}$

Quantidade de voluntários: 114 Alunos da instituição

Dois fiscais ficaram dentro da sala para organizar os formulários nas carteiras, entregando-os aos alunos pedindo se sentassem um pouco afastados uns dos outros.

Dentro da sala, o Pesquisador informava:

Bom dia. Por favor, não mexam nos formulários que estão nas carteiras. Só poderão fazer isso quando for dada autorização.

Meu nome é Agamenon da Costa Melo Segundo. Sou aluno de Pós-graduação da UFRN e responsável pela pesquisa. Obrigada por se voluntariarem e contribuírem para o desenvolvimento desse projeto. Conforme informado, por participarem, vocês poderão ganhar até $\mathrm{R} \$ 10,00$. Isso vai depender do desempenho de vocês na $2^{\circ}$ tarefa que será realizada logo mais.

O tempo médio de duração da pesquisa é de 30 minutos. Só é permitida uma participação por aluno. Então essa é a única vez que vocês poderão participar. Ressaltamos que essa pesquisa é anônima. Não é permitido que vocês façam qualquer assinatura ou marca identificadora em nenhum dos formulários que receberem. Em todos os formulários, haverá apenas o meu nome (Agamenon da Costa Melo Segundo), já que sou o responsável pela pesquisa.

Durante o estudo, não é permitida nenhuma interação entre os participantes. As atividades devem ser realizadas individualmente. Permanecer em silêncio até que vocês saiam da sala é essencial para a realização dessa pesquisa. Por favor, colaborem.

Tudo que for preciso para realizar a pesquisa já foi previamente distribuído. Portanto, deixem todo o material pessoal ao lado da carteira. Por favor, deixem os celulares no modo "silencioso" para não atrapalhar a concentração dos demais.

Gostaria de pedir também que vocês não comentassem com os futuros participantes sobre a dinâmica do estudo (as etapas, todo o processo). Assim todos os participantes vão estar nas mesmas condições: não terão nenhum conhecimento prévio a respeito das atividades que serão realizadas.

Bom, todas as informações necessárias quanto à participação nesse estudo foram repassadas agora. Serão dadas mais informações - como, por exemplo, objetivo da pesquisa e Departamento responsável - quando o estudo for concluído, por meio do site da UFRN, ok?

Alguma dúvida com relação às instruções que eu passei?

\section{Perfil do Respondente e Opinião}

Como vocês podem ver, em cima da carteira de cada um, tem uma folha com o verso em branco voltado para cima. Não desvirem ainda! Essa é a $1^{\text {a }}$ atividade que vocês irão realizar, apenas será traçado um perfil do voluntário e será indagado sua preferência acerca de alguns itens.

Somente na $2^{\circ}$ tarefa, que será realizada logo mais, que vocês terão oportunidade de ganhar até $\mathrm{R} \$ 10,00$.

Essa tarefa consiste em descrever algumas características pessoais, logo, para esta primeira fase da pesquisa, não existem respostas certas ou erradas. Lembremos que não é permitido fazer nenhum tipo de identificação em nenhum local. Vocês terão 8 
minutos cronometrados para realizá-la. Ao meu sinal, vocês irão desvirar a folha e iniciar a atividade.

Vou avisar quando os 8 minutos tiverem acabado e, imediatamente, vocês deverão parar de escrever. Se concluírem a atividade antes dos 8 minutos, por favor, permaneçam sentados na carteira, aguardando o início da próxima atividade, ok?

Alguma dúvida com relação às instruções que eu passei? zerado]

[O Pesquisador pedia para um voluntário conferir se o cronômetro estava

Podem começar! [O Pesquisador iniciava o cronômetro]

Depois de 8 minutos: O tempo acabou! Parem de escrever, por favor.

[O Pesquisador pedia para um voluntário conferir se o cronômetro estava marcando 8 minutos]

Vamos passar agora para a $2^{\circ}$ atividade. Em cima da carteira de cada um, tem 1 envelope. Por favor, peguem o envelope, mas não abram ainda. Dentro do envelope, há um formulário de 3 folhas, com um total de 20 matrizes. Cada tabela tem 12 números de 3 dígitos. Sua tarefa é encontrar uma combinação de 2 desses números que somados cheguem a um resultado igual a 10.

Assim como aconteceu na primeira parte, no enunciado dessa atividade tem o comando do que vocês deverão fazer. As informações fornecidas são suficientes para realizar essa tarefa.

Para cada tabela que vocês resolverem corretamente, conforme o que está sendo pedido, ganharão $\mathrm{R} \$ 0,50$. Se resolverem corretamente as 20 tabelas, $20 \times \mathrm{R} \$ 0,50$, ganharão $\mathrm{R} \$ 10,00$, que é o máximo que vocês podem ganhar. $\mathrm{E}$ assim por diante... Vocês terão 5 minutos cronometrados para realizar essa atividade. Ao meu sinal, vocês irão abrir o envelope pardo, tirar o formulário e iniciar a tarefa. Vou avisar quando os 5 minutos tiverem acabado e, imediatamente, vocês deverão parar de escrever. Se concluírem a atividade antes dos 5 minutos, por favor, permaneçam sentados na carteira, aguardando as próximas informações, ok?

Alguma dúvida com relação às instruções que eu passei? [O Pesquisador pedia para um voluntário conferir se o cronômetro estava zerado]

Podem começar! [O Pesquisador iniciava o cronômetro]

Depois de 5 minutos: O tempo acabou! Parem de escrever, por favor. [O Pesquisador pedia para um voluntário conferir se o cronômetro estava marcando 5 minutos]

Por favor, peguem a ficha de cobrança que foi entregue junto com o primeiro questionário. Vocês irão contar no formulário 2 a quantidade de matrizes que vocês resolveram, ou seja, a quantidade de tabelas em que vocês encontraram e circularam os dois números únicos que quando somados davam resultado exatamente igual a 10 . Depois, vocês irão preencher a ficha de cobrança, escrevendo o número de tabelas resolvidas no espaço indicado.

Como a mesma pesquisa será realizada com outros grupos de voluntários, os formulários contendo as 20 tabelas não poderão sair desta sala em hipótese alguma. Portanto, depois que vocês preencherem o boleto de cobrança, as folhas da $2^{\circ}$ tarefa devem ser, inutilizadas, rasgadas e descartadas na lixeira de coleta seletiva que está no canto da sala [O Pesquisador aponta para a lixeira de coleta seletiva]. Posteriormente, esse material será reciclado. Mais uma vez, gostaria de lembrá-los que não é permitido que vocês façam qualquer assinatura ou marca identificadora nessas folhas.

Depois que preencherem a ficha de cobrança, vocês devem colocar o primeiro formulário dentro do envelope, vão levantar da carteira, um por vez, em ordem, carregando todo o material que receberam: o envelope contendo seus respectivos 
formulários. Irão formar uma fila no corredor à direita, para descartar as folhas da $2^{\circ}$ tarefa (com as 20 tabelas) na lixeira de coleta seletiva e depois formar outra fila para receber o pagamento.

Ao se apresentar ao fiscal, deverá entregar o envelope contendo o boleto de cobrança preenchido e a $1^{\circ}$ atividade dentro do envelope. Ele verá o número que vocês escreveram no boleto de cobrança e pagará $\mathrm{R} \$ 0,50$ por tabela resolvida. Alguma dúvida com relação às instruções que eu passei?

Agora podem contar no formulário de 3 folhas a quantidade de tabelas que vocês resolveram corretamente e preencher o boleto de cobrança em silêncio. Depois coloquem dentro do envelope o primeiro formulário. Formem uma fila para descartar as folhas da $2^{\mathrm{a}}$ tarefa e depois outra para receber o pagamento. Lembrando, mais uma vez, que não é permitida nenhuma interação entre os participantes até que vocês tenham saído da sala. Vou aguardá-los ao lado da lixeira. [O Pesquisador ficava ao lado da lixeira de coleta seletiva para assegurar que todos iriam descartar as folhas da $2^{\circ}$ tarefa (com as 20 tabelas). O Fiscal, que estava dentro da sala, perto da porta, organizava a fila para recebimento do pagamento].

Um voluntário por vez saiam da sala e se dirigiam ao local onde seria feito o pagamento. Cada voluntário devolvia ao fiscal a ficha de cobrança preenchida e o envelope contendo a folha da tarefa 1 . O fiscal via o número de tabelas que afirmaram ter resolvido (o número que escreveram na ficha de cobrança) e pagava $\mathrm{R} \$ 0,50$ por resposta certa. O fiscal colocava a ficha de cobrança dentro do respectivo envelope de cada um. 